\title{
Using rank-frequency and type-token statistics to compare morphological typology in the Celtic languages
}

Andrew Wilson* and Rosie Harvey

Department of Linguistics and English Language, Lancaster University, Lancaster, UK

Provide full correspondence details here including e-mail for the *corresponding author

Department of Linguistics and English Language, Lancaster University, County South Building, Lancaster LA1 4YL, UK

a.wilson@lancaster.ac.uk

Provide short biographical notes on all contributors here if the journal requires them.

N/A 


\title{
Using rank-frequency and type-token statistics to compare morphological typology in the Celtic languages
}

\author{
Tristram (2009) applied Greenberg's (1960) synthetism index to compare three of \\ the Celtic languages: Irish, Welsh, and Breton. She did not analyse samples of \\ the other three Celtic languages - Scottish Gaelic, Manx, and Cornish. This \\ paper expands on her work by comparing all six Celtic languages, including two \\ periods of Irish (Early Modern and Present Day). The analysis is based on a \\ random sample of 210 parallel psalm texts (30 for each language). However, \\ Greenberg's synthetism index is problematic because there are no operational \\ standards for counting morphemes within words. We therefore apply a newer \\ typological indicator (B7; Popescu, Mačutek \& Altmann, 2009), which is based \\ solely on lexical rank-frequency statistics. Following Kelih (2010), we also \\ explore whether type-token counts alone can provide similar information. The \\ B7 indicator shows that both varieties of Irish, together with Welsh and Cornish, \\ tend more towards synthetism, whereas Manx tends more towards analytism. \\ Breton and Scottish Gaelic do not show a clear tendency in either direction. \\ Rankings using type-token statistics vary considerably and do not tell the same \\ story.
}

Keywords: typology; synthetism; rank-frequency statistics; type-token statistics; Celtic.

\section{Introduction}

In this paper, we explore the application of a newer generation of typological indicators, based on lexical rank-frequency and type-token statistics, to examine the structure of the Celtic group of languages on the morphological dimension of synthetism versus analytism. In doing so, we expand on earlier work by Tristram (2009), who examined just three of these languages using Greenberg's original (1960) synthetism index. We provide a comparison of all six Celtic languages, including two different periods in the development of Irish. We also place Celtic typology in the context of a number of other world languages, using the data provided by Popescu, Mačutek \& Altmann (2009). 
The Celtic languages are traditionally divided, on genetic grounds, into two groups: Q-Celtic (or Goidelic) and P-Celtic (or Brythonic). The names Q-Celtic and PCeltic refer to the reflexes of an hypothesized Proto-Indo-European labiovelar $\left(* k^{w}\right)$, which evolved to become a velar plosive in Q-Celtic and a bilabial plosive in P-Celtic e.g., in the word for "four" (* $k^{w}$ etuor), which, for instance, in modern Welsh became pedwar and in modern Manx kiare. Of the three attested Q-Celtic languages, Irish is the oldest, with Scottish Gaelic and Manx being later independent developments from it. There are similarly three attested P-Celtic languages, namely Welsh, Cornish, and Breton. All six of the modern Celtic languages are currently spoken, although the present-day versions of Cornish and Manx stem largely from revival movements in the 20th and 21st centuries; Cornish was effectively a dead language by the end of the 19th century (Mills, 2010), whilst the native-speaker continuity of Manx since the middle of the 1970s has been the subject of some debate (see Ager, 2009). ${ }^{1}$

Different approaches to language typology can be considered (Popescu \& Altmann, 2008a). Some, traditionally, focus merely on classifying languages, either by tracing their genetic descent or, empirically, in terms of specific shared characteristics. Others, however, attempt to move away from mere classification, towards explanation. This latter course is characteristic of contemporary linguistic synergetics, which attempts to account for the nature of language itself by means of laws that are generally applicable across all known languages. A synergetic approach to typology attempts to derive and account for classifications of languages (and other groupings of linguistic entities, such as text types) in terms of variations in those laws. These variations are

\footnotetext{
${ }^{1}$ Further information about the Celtic languages can be obtained from the standard overviews by Ball \& Fife (1993), MacAulay (1992), and Russell (1995).
} 
distinct from the rules and exceptions of many traditional linguistic theories because they must be derivable mathematically from the general statement of the relevant language law: they cannot be simply a list of ad hoc additions or exceptions (Köhler, 1987).

Notwithstanding the shift of emphasis from mere classification to explanation, a continuing focus of interest has been in the morphological typology of languages. Whilst a number of different typologies have been proposed, one of the more enduring contrasts has been the distinction between synthetic and analytic languages. This has its classic statement in the work of Sapir (1921). A "purely" analytic language is one that has only one meaningful unit (morpheme) per word form, whilst a "purely" synthetic language is one that has more than one morpheme per word form. Sapir (1921) also added the term "polysynthetic" to describe those languages that have a particularly high number of morphemes per word. However, it is clear that most languages cannot be classified straightforwardly as synthetic or analytic (or even polysynthetic) but, rather, occupy a place on a continuum, such that they are "more analytic than synthetic", or vice versa. For example, the simple English sentence She was running tends somewhat towards analytism (in contrast to one of its possible Latin equivalents, currebat, where the subject's gender is derived only from the context and all other information about tense and aspect is encoded in the verb inflection); but it nevertheless still involves the inflection (or, rather, suppletion) of the verb to be as was and the inflection of the verb to run by the addition of the -ing suffix.

Greenberg (1960) took Sapir's work a step further by describing a number of quantitative indices for morphological typology, including a simple synthetism index, $\mathrm{M} / \mathrm{W}$, which measures the proportion of morphemes (M) to running words $(\mathrm{W})$ in a representative text sample. Undertaking a preliminary analysis on eight languages, he 
noted that "even cursory inspection of the indices set forth here shows that, if we define an analytic language as one with a synthetic index of 1.00-1.99, synthetic as 2.00-2.99, and polysynthetic as $3.00+$, the results would conform to the usual nonquantitative judgments" (p. 194).

Tristram (2009) applied Greenberg's synthetism index to a number of different periods, dialects, and text types of three out of the six Celtic languages - namely Irish, Welsh, and Breton. For Old Irish, she obtained a mean synthetism index of 3.57 (SD 0.03), for Classical Irish 2.14 (SD 0.22), for modern Irish 1.94 (SD 0.04), and for modern Breton 1.68 (SD 0.17). ${ }^{2}$ The results for Welsh she took from Parina's earlier (2006) study: for Old Welsh the synthetism index was 1.28 and for modern Welsh it was $1.35 .^{3}$ Using Greenberg's (1960) rule of thumb, this means that Old Irish can be categorized as "polysynthetic", Classical Irish as "synthetic", and Welsh and Breton as "analytic". Modern Irish stands very much on the border of "synthetic" and "analytic" (1.94, close to Greenberg's cut-off of 1.99). However, as we suggested earlier, it is probably preferable to avoid simplistic classifications and to talk rather of stronger or weaker tendencies along the analytic-synthetic continuum. Unfortunately, Tristram did not analyse any texts from the remaining three Celtic languages - Scottish Gaelic, Manx, and Cornish. Though she actually cites time pressures as her grounds for doing so, the omission of Scottish Gaelic is, to a certain extent, excusable for theoretical reasons, since Classical Irish functioned as the literary language of Gaelic Scotland until

2 We do not include all of Tristram's statistics here, only those which have a bearing on the present experiment.

3 No standard deviations are given for the Welsh statistics from Parina (2006), as she only analysed one text sample per period. Furthermore, two different figures are provided for Welsh, depending on whether word-initial mutations are included in the morpheme counts. Generally, it seems that Tristram does not consider the mutations as morphemic. It is worth noting that Parina (2006) also analysed a text that is closer in date to our own sample - John 1.1-7 from the Welsh Bible of 1588. This had a synthetism index of 1.42 (ignoring mutations). However, this result makes no difference to Tristram's rankings of languages. 
at least the 18th century (MacCoinnich, 2008). Nevertheless, it would be interesting to know how Scottish Gaelic has evolved since then, in comparison with both Classical Irish and Present-Day Irish. As regards the other two languages (Manx and Cornish), Tristram (2009, p. 256) gives the misleading impression that they are no longer spoken: "Von diesen Sprachen werden heute noch vier gesprochen: das Walisische, Bretonische, Irische und Schottisch Gälische”. This is untrue (see, e.g., Ager, 2009; Mills, 2010); sufficient textual material - both historical and contemporary - is, in fact, available for both Manx and Cornish.

An important point about Greenberg's synthetism index is that it requires a fairly deep knowledge of the grammar and semantics of a language in order to apply it reliably. Indeed, it is questionable whether it can be applied reliably at all, unless very clear operational criteria are laid down for the definition of words and morphemes. For instance, in a further study, Tristram (2010) asked 32 specialists in Old Irish to code a selection of eight orthographic word forms with, first, a word count and, second, a morpheme count. Fourteen people responded, to which she also added her own analyses, giving a total of fifteen suggested analyses. The suggested word counts for these single orthographic forms ranged from one to three (with unanimous agreement on only two out of the eight word forms), and the morpheme counts ranged from two to ten (with no unanimous agreement on any of the eight word forms). These results suggest not only that Greenberg's index is difficult, or at least unreliable, to apply, even when used by experts in a given language, but also that any published analyses that use it should be approached with a degree of caution. Whilst some of the broader conclusions that are based upon it may not be entirely misleading, it should certainly not be seen as the decisive "gold standard" for the quantitative study of language typology. 
But this is not the only problem with Greenberg's indices. For one thing, even if the language constructs on which they are based can be defined operationally to an acceptable degree of inter-rater reliability, these analyses will still involve a fairly substantial manual effort, given that the automatic morphemic analysis of unrestricted text is not a straightforward task for natural language processing. Simpler alternative indicators that can measure the same theoretical constructs reliably are therefore to be welcomed.

Drawing on data from twenty languages, which included known extremes of synthetism and analytism, Popescu and Altmann (2008b) demonstrated that a rankfrequency-based indicator, known as $B$, could be used to help gauge the tendency of a language towards synthetism or analytism. In a book-length treatment of aspects of word frequencies (Popescu, Mačutek \& Altmann, 2009), they later added a number of other possible rank-frequency-based indicators to this one. In the 2009 book, it should be noted that they also renamed the earlier indicator $B$ as $B 7$. This name will be used in the remainder of the present paper.

\section{Derivation of indicator B7}

Perhaps the simplest thing that can be done with a machine-readable text is to produce a frequency list of the word forms within it. When presented in descending order of frequency, with each word-type assigned a serial number from 1 (the most frequent) to V (the least frequent), this then becomes a ranked frequency list. Ranked frequency lists are most often used to gain an insight into the content of a text, based on the assumption that the words that are used most frequently - at least in so far as they are autosemantic (i.e. 'open-class' or 'content') words - are also those which are most central to the theme(s) of the text. However, setting aside the actual words that are 
used, the purely formal properties of a ranked frequency list can also provide typological information for the linguist.

To almost any rank-frequency list, it is possible to fit the Zipfian (also known as the Zeta or power) function:

$$
f_{r}=\frac{a}{r^{b}}
$$

where $r=$ the rank of a given word, $f_{r}=$ the frequency of this word, and $a$ and $b$ are parameters to be estimated. However, the theoretical Zipfian curve typically does not fit naturally occurring data exactly and usually crosses the observed frequencies at some point within the range of the hapax legomena (words occurring only once). Popescu and Altmann (2008a) have observed that, if the curve crosses the observed frequencies early, so that most of the hapax legomena lie above the curve, this indicates a tendency to synthetism; however, if the curve crosses the observed frequencies late, so that most of the hapax legomena lie below the curve, then this indicates a tendency to analytism. This is because the more analytic languages will tend to use the same word-form multiple times to communicate a concept (it does not change to signal different grammatical relations - e.g. subject vs. object), whilst the more synthetic languages will use a greater number of unique forms (because the same lexeme changes its form to signal grammatical information). In the former case, the theoretical curve underestimates the number of hapax legomena, hence the predicted frequencies lie above the observed frequencies for longer; in the latter case, the theoretical curve overestimates the number of hapax legomena, hence the predicted frequencies fall below the observed frequencies at an earlier stage.

Popescu and Altmann (2008b) go on to point out that, in the former case, the mean of the Zipfian function must be smaller than the empirical mean of the observed data. The empirical mean of the data is given by: 


$$
M_{e}=\bar{r}=\frac{1}{N} \sum_{i=1}^{V} r f_{r}
$$

where $N$ is the number of tokens in the text, $V$ is the number of types, $r$ are the ranks, and $f_{r}$ is the frequency of the word at rank $r$. The mean of the Zipfian function $\left(M_{f}\right)$ is given by the same equation, but substituting the predicted frequency for the observed frequency.

The indicator B7 is then given by:

$$
B 7=\frac{M_{e}-M_{f}}{M_{e}}
$$

and it has the properties that, if B7 is greater than zero, the language tends more towards synthetism and, if B7 is less than zero, the language tends towards analytism.

As regards the other indicators proposed by Popescu, Mačutek \& Altmann (2009), named B8 and B9, neither of these has, so far, a stated range of "analytic" versus "synthetic" tendencies. Furthermore, they are rank-order identical with the indicator B7, and all three can be derived mathematically from each other. For these reasons, we do not consider the indicators B8 and B9 any further in our experiment.

\section{Materials and methods}

The data chosen for this study consists of a parallel translation corpus of thirty psalms in all six of the Celtic languages, i.e., Welsh, Scottish Gaelic, Cornish, Breton, Manx, and Irish. For Irish, we were also able to consider two different time periods: Early Modern Irish and Present-Day Irish. (Early Modern Irish corresponds to what Tristram [2009] calls "Classical Irish".) In total, then, our sample contains 210 individual texts.

The thirty psalms were selected at random, ignoring texts numbered higher than 111 , as these were not readily available in two of the language varieties analysed (i.e. Breton and Early Modern Irish). The psalms analysed were numbers 1, 2, 3, 6, 12, 17, 
$20,21,27,28,29,32,41,42,43,51,54,56,79,81,84,85,90,91,95,96,97,98,99$, and 101 .

Using bibliographic data, the various translations can be dated roughly as follows:

- Welsh

- Early Modern Irish

- Manx

- Scottish Gaelic

- Breton

- Cornish

- Present-Day Irish ca. 1620

ca. $1640-1685$

1765

1794

1893 (revised in 2004-2011)

1997

2004

The use of parallel translation texts should provide a fair comparison of the six Celtic languages, in so far as it largely allows us to rule out variation owing to content, text type, text length, etc. For Irish, as has already been noted, it has also been possible to process texts from the Early Modern and contemporary eras, giving some insight into diachronic developments over the course of roughly 350 years. However, in other cases, it was simply not possible to avoid, or to control for, differences in date whilst retaining a parallel translation corpus covering all of the Celtic languages. In a couple of cases, this was due simply to issues of access and copyright, but there were other reasons too. For instance, in contrast to most of the other languages, no Cornish translation of the psalms had been produced prior to the translation used here, which dates from as late as 1997. A Breton version was also quite late in coming; the text used here originates in the late 19th century, but it has been subjected to some modernization more recently, in 2004-2011. 
In order to calculate the typological indicator B7, it is necessary to produce a rank-frequency list of the words in each text in each language. (We do not mix the texts into aggregated corpora because this introduces heterogeneity and affects the properties of the Zipfian distribution - see Altmann, 1992.) The production of the rank-frequency lists was achieved using a bespoke word-counting program written in Ruby 1.8 . However, prior to producing the lists, it was first necessary to decide on how the texts were to be tokenized.

Tokenization is not a trivial problem for the Celtic languages, since hyphenation (especially in Manx) and the use of apostrophes (especially in Irish and Scottish Gaelic) are both commonplace. More generally, each of the languages has its own conventions governing the use of punctuation marks, division into orthographic word forms, and so on. However, orthographic conventions are merely that: conventions. Furthermore, most of them substantially post-date the texts being analysed here and have a prescriptive, rather than a merely descriptive, role. If we are looking for systematic relationships and differences between languages, we need to use tokenization criteria that are minimally theory-bound and independent of the post-hoc decisions of the codifiers of individual languages. However, even phonetic transcriptions of spoken texts would not help us here, since their tokenization into words for counting is still an artificial task governed by rules derived from grammars, dictionaries, and the orthographic conventions just mentioned. (A detailed consideration of tokenization issues, exemplified on the Slavic languages, can be found in Antić, Kelih and Grzybek, 2006.)

For the present experiment, it was therefore decided to tokenize all of the lists using broadly the same cross-linguistic conventions that have been applied for over a decade in the systematic study of word-length typology (Best, 2009). Thus, a word was 
defined as being a string of printed characters with white space or punctuation at either end. Internal hyphens were treated as part of the word, so that a form such as the Manx cur-jee counts as one word and not two. In our study, apostrophes were always treated as part of a word, even when they occurred at the beginning or end of a string (but excluding cases which were obviously quotation marks). For instance, Scottish Gaelic distinguishes orthographically between, e.g., $m$ ', ' $m$, and $m$; these three forms represent different underlying lexemes, but their disambiguation or lemmatization lies beyond the scope of this experiment (and also contradicts its aim of a rapid, minimally knowledgebased assessment of typology). Further special cases covered by Best's conventions i.e., numerals, abbreviations, and acronyms - did not occur in these data.

The rank-frequency lists were then read into the $\mathrm{R}$ environment for statistical computing (Ihaka \& Gentleman, 1996) and the Zipfian distribution fitted using the $n l s$ function for nonlinear regression. Using the parameter estimates from this stage, the typological indicator B7 was calculated for each text. A measure of goodness of fit was also calculated for the Zipfian distribution. This is the determination coefficient $\mathrm{R}^{2}$, which is given by:

$$
R^{2}=1-\frac{\sum_{r=1}^{V}\left(f-f_{\text {pred }}\right)^{2}}{\sum_{r=1}^{V}(f-\bar{f})^{2}}
$$

where $f$ is the observed frequency and $f_{\text {pred }}$ is the predicted frequency. A good fit is indicated by $\mathrm{R}^{2}>0.9$; a fit is still acceptable when $\mathrm{R}^{2}>0.8$ (but in psychology one allows even smaller $\mathrm{R}^{2}$ ).

\section{Results}

Appendix 1 shows the values of the indicator B7 for each of the 210 individual texts. It also shows the type $(\mathrm{N})$ and token $(\mathrm{V})$ counts for each text, as well as the parameter estimates ( $A$ and $b)$ and goodness of fit $\left(R^{2}\right)$ for the Zipfian function. 
Figure 1 summarizes the B7 values for each language in the form of a boxplot, together with the mean values. The means are also presented in Table 1, along with their standard deviations and $95 \%$ t-confidence intervals. The confidence intervals are depicted visually in Figure 2.

\section{INSERT FIGURE 1 HERE}

\section{INSERT TABLE 1 HERE}

\section{INSERT FIGURE 2 HERE}

It will be seen from Table 1 and Figure 2 that Early Modern Irish has the highest mean B7 (i.e., the highest degree of synthetism), followed (in descending order) by Present-Day Irish, Welsh, Cornish, Breton, Scottish Gaelic, and finally Manx.

The indicator B7 makes a clear statement about where the theoretical dividing line between analytic and synthetic tendencies falls; the more synthetic languages will show values of B7 in the positive range, whereas the more analytic languages will fall in the negative range. Both varieties of Irish, together with Welsh and Cornish, can thus be said to tend more towards synthetism, whilst Manx tends more towards analytism. Breton and Scottish Gaelic fall very much on the dividing line between synthetism and analytism, just into the negative (analytic) range of the indicator. However, it should be remembered that these figures are means, calculated from thirty individual texts per language. To check the degree of a tendency in one direction or the other, whilst taking sampling error into account, we therefore also calculated $95 \%$ t-confidence intervals for the means. If a confidence interval includes zero, then, on the basis of the current evidence, we cannot reject the hypothesis that the mean value of B7 for that language could, in fact, be zero. However, if the upper and lower ends of the interval both fall on the same side of zero, we may infer that the value of B7 also falls on that side of zero. 
This means that, for Breton and Scottish Gaelic, we cannot reject the hypothesis that the value of B7 is zero; for the other languages, we do reject this hypothesis.

Although we had reason to question the reliability of Greenberg's original (1960) synthetism index, it is nevertheless of interest to compare these results with Tristram's (2009) calculations. Both her study and ours suggest that Early Modern Irish (which she refers to as "Classical Irish") tends the most towards synthetism. However, that is where the similarities end. Tristram reported that Present-Day Irish tended towards analytism, whereas our results suggest it tends towards synthetism. Tristram's results also suggested that both Welsh and Breton are analytic, whereas our results suggest that Welsh tends towards synthetism, whilst Breton cannot be classified clearly as either synthetic or analytic.

As mentioned earlier, however, it is perhaps more meaningful to consider all of the Celtic languages together on a single continuum from analytic to synthetic, and then to compare the ranking of the languages, rather than merely their binary classifications. Examining Figures 1 and 2 suggests that there may be three groupings within the data, with Manx, Scottish Gaelic, and Breton having a "low" B7; Cornish, Welsh, and Present-Day Irish having an "intermediate" B7; and Early Modern Irish having a "high" B7. (We have placed these descriptors within quote marks, because they are only relative, within the present set of languages.) To test for statistically significant differences between the individual pairs of languages, we calculated a set of pairwise Welch-Satterthwaite confidence intervals for the differences in means (Welch, 1947). Owing to the relatively large number of pairwise comparisons (21), we applied a Bonferroni correction to keep the family-wise Type I error rate below 5\%. For pairwise confidence intervals, the Bonferroni formula is:

$$
100-\frac{(\alpha / 100)}{m}
$$


where $\alpha$ is the desired family-wise Type I error rate (as a percentage) and $m$ is the number of pairwise intervals being calculated. For our data, this computed as:

$$
100-\frac{(5 / 100)}{21}=99.9976
$$

meaning that we needed to calculate a set of $99.9976 \%$ intervals, rather than the usual 95\% intervals. These are shown in Table 2 and, graphically, in Figure 3. The test for each pair of languages is then whether the null hypothesis of no difference (i.e. zero) falls within the interval or not; if it does not, then we reject the null hypothesis for that pair, otherwise we cannot reject it on the basis of these data.

From Table 2 and Figure 3, we see that Early Modern Irish, which has the highest mean B7, is significantly different from all the other languages. Below that, Welsh, Cornish, and Present-Day Irish are also all significantly different from Manx, which has the lowest mean B7. The only other two significant differences are between Scottish Gaelic and Present-Day Irish (borderline, with zero at the very end of the interval), and between Scottish Gaelic and Welsh. The tests thus broadly support the informal inference from Figures 1 and 2 - namely, that there exist three levels of "low", "middle", and "high" ranking languages on the B7 indicator. However, the positions of Scottish Gaelic and Breton are ambiguous. The mean of Scottish Gaelic differs significantly from two members of the "middle" group (Welsh and Present-Day Irish), but not from the third member, Cornish. It is also not significantly different from Manx, hence it appears to occupy a borderline position between the "low" and "middle" ranks. Breton is not significantly different from any other language, apart from Early Modern Irish, and can thus not be classified straightforwardly as having either a "low" or a "middle" mean value of B7.

There were four languages in common between this experiment and Tristram's: Welsh, Breton, Early Modern Irish, and Present-Day Irish. Tristram reported that Welsh 
ranked as the most analytic of these four, followed in order by Breton, Present-Day Irish, and Early Modern Irish. Our results suggested that Breton is the most analytic of the four, followed by Welsh, Present-Day Irish, and Early Modern Irish. However, as the difference in means between Breton and Welsh was not statistically significant, we cannot claim that our ranking is any different from the ranking obtained by Tristram; we are seeing broadly the same pattern.

Perhaps the most interesting finding in our study actually relates to two of the languages that Tristram (2009) did not consider. Manx shows an unusually high degree of analytism when compared to the two diachronic varieties of Irish (both quite strongly synthetic), as does Scottish Gaelic, though to a marginally lesser extent. Again, further research is required to properly support and account for this finding, which is suggestive of an important diachronic divergence within the Q-Celtic branch. It is clear that the developments in Manx and Scottish Gaelic are not of very recent origin, since the data processed here for both languages date from the 18th century. Unfortunately, however, the written tradition in Manx began only in the 17th century (Sebba, 1998), making investigations of its earlier history difficult. Similarly, a distinctive written literature in Scottish Gaelic does not begin to emerge until around this time (MacCoinnich, 2008, p. 330).

In terms of how the Celtic languages compare with a number of other world languages, we can compare our B7 values with those obtained by Popescu, Mačutek \& Altmann (2009, p. 115). As all of our data were parallel psalm texts, and Popescu, Mačutek \& Altmann used different quantities of texts drawn from different text types, a strict statistical comparison would not be appropriate. However, some raw comparisons of the means may nevertheless help to contextualize our results and suggest hypotheses for future comparative studies. That said, then, our most synthetic language, Early 
Modern Irish, shows a value of B7 that is fairly close to that obtained for German (0.0738). This is lower (i.e. more analytic) than the value for Latin (0.1612) and considerably lower than the most synthetic of Popescu, Mačutek \& Altmann's languages, Hungarian (at 0.6309). Our most analytic language, Manx, does not have a very close counterpart in Popescu, Mačutek \& Altmann's list; however, it falls in the span between Bulgarian (0.0055) and Indonesian (-0.0501). Breton and Scottish Gaelic also fall inside this span. According to Kelih (2010), Bulgarian (along with Macedonian) has the most limited morphological case-flexion system of all the Slavic languages. However, this still means that our most analytic Celtic language ranks as considerably less analytic than other Indo-European languages such as Italian (-0.0744) and English (-0.1617). It is also far less analytic than the most analytic language in Popescu, Mačutek \& Altmann's study - Hawaiian - which had a mean B7 of $-1.2484 .{ }^{4}$ The three remaining Celtic languages in the middle of our rankings - Present-Day Irish, Welsh, and Cornish - all show B7 values that are similar to that obtained for Russian (0.0349).

\section{Type-token statistics}

A final footnote to the present experiment seems appropriate. Kelih (2010) examined a parallel translation corpus of the twelve Slavic languages - a set of translations of the novel How the steel was tempered by N.A. Ostrovskij. His aim was to examine how far the raw type-token statistics might function as an indicator of language typology,

\footnotetext{
${ }^{4}$ The figure quoted by Popescu, Mačutek \& Altmann (2009) for Hawaiian is actually -12.484 , but this is clearly a misprint; recalculation from their table of individual text statistics shows that the correct value is -1.2484 .
} 
without any need to consider fitting the Zipfian (or any other) function. This makes some sense, because an increase in the number of hapax legomena, which is the key underlying factor for all of the rank-frequency-based indicators in Popescu, Mačutek \& Altmann (2009), necessarily leads to a change in the overall type-token relationship. Kelih (2010) found that his ranking of token counts matched very closely the traditional sub-classification of the Slavic languages into the South, West, and East Slavic branches. However, the clustering was less evident in the type counts and hardly visible at all when the type and token counts were taken together.

Perhaps the simplest way to compare type and token counts is to make a scatterplot, as Kelih did. However, with the present data, we have thirty distinct texts for each language, which leads to a far more complex plot (Figure 4) than Kelih had for his data, where only one data point per language was plotted. It is, in fact, difficult to establish any clear pattern of clustering using this graph, except to note a general linear increase of type counts in relation to token counts. This is clearly because we are combining texts with quite different lengths on a single plot.

\section{INSERT FIGURE 4 HERE}

One alternative would be to produce a set of thirty scatterplots, one for each parallel psalm. However, these would be quite difficult to analyse systematically in terms of two-dimensional clustering patterns. A more straightforward alternative is to calculate a single summary measure - the token-type ratio (TTR) - for each language on each psalm:

$$
T T R=\frac{N}{V}
$$

where, as before, $\mathrm{N}=$ the number of tokens and $\mathrm{V}=$ the number of types. The individual TTR values are shown in Appendix 2. However, as it is well known that the TTR grows larger with increasing $\mathrm{N}$, independently of $\mathrm{V}$, we refrained from 
undertaking a numerical comparison of the means for each language. ${ }^{5}$ Instead, we took each psalm in turn and ranked the TTR values for the different languages. We then counted how often each language occupied each rank position across the thirty psalms (Table 3).

\section{INSERT TABLE 3 AROUND HERE}

It can be seen from Table 3 that Welsh nearly always has the highest TTR; it ranks first for 28 out of the thirty psalms. However, the pattern amongst the remaining languages is less constant. There are a couple of other noticeable trends: Breton occurs 23 times within the top three ranks, whilst Present-Day Irish and Manx both occur frequently within the bottom three ranks (29 and 27 times, respectively). This might seem, at first glance, to suggest a split along the conventional P-versus Q-Celtic lines; but, apart from Welsh, it has to be noticed that no language occupies a single rank for more than around half of the total number of psalms (16 being the next highest cell frequency). Early Modern Irish, in particular, is quite evenly dispersed across all rank positions, apart from the first; and Cornish and Scottish Gaelic also show quite even dispersion across a range of three or four different rank positions. Overall, then, these figures do not seem to provide any consistent support for a ranking of the languages in terms of the type-token relationship.

We should return finally, however, to Kelih's (2010) observation that, in his study, the relationship between type-token statistics and typology was only clearly reflected in the token counts. To test for this with our data, we undertook a similar

\footnotetext{
${ }^{5}$ In our case, Spearman's rho for the relationship between TTR and N was 0.409 (p <
} 0.001) but, for the relationship between TTR and V, rho was just -0.0098 ( $\mathrm{p}=$ $0.8869)$. 
analysis to the previous one, but using the token counts in place of the TTR values. In other words, we took each psalm in turn, ranked the token counts for the different languages, and then counted how often each language occupied each rank position across the thirty psalms. The results are shown in Table 4.

\section{INSERT TABLE 4 AROUND HERE}

As with the TTR, the token-count patterns are not conclusive, with only one cell of Table 4 showing a frequency higher than 15 out of thirty. On the whole, however, Present-Day Irish and Cornish tend to have the smallest token counts (falling, respectively, 28 and 24 times out of thirty in the bottom two ranks). Scottish Gaelic and Welsh have the highest counts (falling 25 and 26 times, respectively, in the top two ranks). Breton falls mostly in the middle of the range, occupying the middle three ranks for 25 times out of thirty. Early Modern Irish shows a similar pattern to Breton, falling 24 times out of thirty in the middle three ranks. Taken together, these rankings do not match either the results from our analysis of the B7 indicator or the traditional division into the P- and Q-Celtic sub-groups. It would appear, then, that Kelih's (2010) success in clustering his Slavic parallel texts according to the traditional sub-classification of languages does not replicate consistently for our Celtic parallel texts.

\section{Discussion}

This study has examined the application of a newer quantitative typological indicator, named B7, to the Celtic languages. This indicator is distinctive from other earlier typological indicators (such as Greenberg's [1960] synthetism index) in that it requires no morphological analysis but relies purely on lexical rank-frequency statistics.

In so far as comparative data have been available (which was the case for Early Modern and Present-Day Irish, Welsh, and Breton), the indicator B7 provided quite 
similar results to Greenberg's synthetism index, as computed by Tristram (2009), when considered as rankings on a continuum; however, there was a greater degree of discrepancy when the binary classification of languages into analytic versus synthetic was considered. Although this broad similarity in rankings is pleasing, we do not consider the comparison as a gold-standard test of the indicator B7, for the reasons discussed in the Introduction.

The indicator B7 suggested not only that Irish had evolved diachronically from a greater to a lesser degree of synthetism but also that the overall synthetic versus analytic tendencies within Celtic were not straightforwardly linked to the ancestral Q- versus PCeltic classification. This picture was not visible in Tristram's (2009) study, since she had not computed synthetism indices for Scottish Gaelic, Manx, or Cornish. In the present study, Manx (a Q-Celtic language) was the most analytic of all, whereas two of the other Q-Celtic languages (i.e. Early Modern and Present-Day Irish) both tended quite strongly towards synthetism; in contrast, Welsh (a P-Celtic language) proved to be more synthetic than both Manx and Scottish Gaelic (the other Q-Celtic language). Cornish was also more synthetic than Manx, but the difference with Scottish Gaelic was not statistically significant. Since the diachronic tendency in most Indo-European languages has been to move away from synthetism towards analytism, it seems unlikely that disparities in date lie behind these results: indeed, the Cornish texts are some of the most recently composed in this study, whereas the Manx texts only post-date the Early Modern Irish data by about a century. It thus seems, from these figures, that Manx especially (but also, to a slightly lesser extent, Scottish Gaelic) evolved earlier and more decisively towards analytism than has the present-day standard written variety of Irish on the island of Ireland. This view can be supported by comments in the nonquantitative literature. For instance, Broderick (1999, p. 77) has noted that, after the 
fifteenth century, "Manx became more progressive in its development from a synthetic to an analytic type". Similarly, when writing about the verbal system in a spoken dialect of Irish that is considered to be particularly close to Scottish Gaelic (Rathlin Island, Co. Antrim), Holmer (1942, p. 129) noted that "[t]he analytic conjugation, which is typical of Scottish Gaelic, is properly a simplification of the original synthetic conjugation, and the former is gaining ground also in Northern Irish, especially among the younger generation". In other words, by the time Holmer was writing, Scottish Gaelic had already shifted in the direction of analytism, but some spoken dialects of Irish were only just starting to move in that direction through the influence of younger speakers. We cannot firmly identify any similar trends within the P-Celtic group, since none of the pairwise contrasts between Welsh, Cornish, and Breton were statistically significant.

Comparison with the B7 values obtained for a range of other languages by Popescu, Mačutek \& Altmann (2009) showed that our most synthetic language, Early Modern Irish, demonstrates a similar degree of synthetism to modern German, which, in turn, is less synthetic (according to this indicator) than Latin. However, the maximal degree of shift towards analytism within Celtic (with Manx being the only language that has a mean B7 significantly on the negative side of zero) is considerably less than has occurred in some other modern Indo-European languages, such as English and Italian. It would be interesting to analyse some more recent Manx data using B7, to see whether there has been any further shift towards analytism since the eighteenth century.

Following on from Kelih's (2010) consideration of the Slavic languages, the study also looked at whether simple type-token statistics could be used for typological classification, in place of calculating an indicator such as B7, which requires the prior fitting of the Zipfian function. However, the results from this analysis showed few 
conclusive tendencies. Neither the summary Token-Type Ratio (TTR), nor the token count alone (which succeeded in Kelih's study), produced rankings where most of the languages fell in the same rank position on more than fifteen out of the thirty parallel psalm texts in our sample. Comparing broader tendencies (i.e. taking two or three contiguous rank positions at a time) showed some degree of patterning (especially for the token counts alone) but did not match with either the B7 results or the traditional classification of the languages into P- and Q-Celtic.

In summary, the present research, despite drawing only on psalm texts, and with severe limitations on controls for date, suggests that the typological indicator B7 may be of considerable value in investigating typological variation across the world's languages. Certainly, the story that it tells in relation to these Celtic texts ties in very well with the accounts of Celtic language change that can be found in more traditional qualitative scholarship. Further work, drawing on other text types and other dates in the history of Celtic, will surely tell interesting stories, not only about language evolution but also about text typology within individual languages. However, the future value of using raw type-token statistics for typological purposes seems unclear to us. 


\section{Data sources}

Welsh

http://justus.anglican.org/resources/bcp/

Breton

http://bibl.monsite-orange.fr/

$\operatorname{Manx}$

http://mannin.info/MHF/

Cornish

Courtesy of Keith Syed, Cornish Bible Project

Scottish Gaelic

Digital Archive of Scottish Gaelic, Text No. 152 (http://www.dasg.ac.uk)

Present-Day Irish

https://www.ireland.anglican.org/prayer-worship/book-of-common-prayer/2004-texts

Early Modern Irish

http://macmate.macace.net/ macfhionn@ macace.net/index.html/Psailm.html 


\section{References}

Ager, S. (2009). A study of language death and revival with a particular focus on Manx Gaelic. MA dissertation, Bangor University.

Altmann, G. (1992). Das Problem der Datenhomogenität. In B. Rieger (Ed.), Glottometrika 9 (pp. 287-298). Bochum: Brockmeyer.

Antić, G., Kelih, E. \& Grzybek, P. (2006). Zero-syllable words in determining word length. In P. Grzybek (Ed.), Contributions to the science of text and language: Word length studies and related issues (pp. 117-156). Dordrecht: Springer.

Ball, M.J. \& Fife, J. (Ed.) (1993). The Celtic languages. London: Routledge.

Best, K.-H. (2009). Quantitative Linguistik: Einführung und "Führer” zur Sprachstatistik des Deutschen sowie Principles for Word-Length Count. Retrieved July 25, 2011, from http://wwwuser.gwdg.de/ kbest/einfueh.htm

Broderick, G. (1999). Language death in the Isle of Man. Berlin: Walter de Gruyter.

Greenberg, J.H. (1960). A quantitative approach to the morphological typology of languages. International Journal of American Linguistics, 26, 178-194.

Holmer, N.M. (1942). The Irish language in Rathlin Island, Co. Antrim. Dublin: Royal Irish Academy.

Ihaka, R. \& Gentleman, R. (1996). R: A language for data analysis and graphics. Journal of Computational and Graphical Statistics, 5, 299-314.

Kelih, E. (2010). The type-token relationship in Slavic parallel texts. Glottometrics, 20, $1-11$.

Köhler, R. (1987). Systems theoretical linguistics. Theoretical Linguistics, 14, 241-257. MacAulay, D. (Ed.) (1992). The Celtic languages. Cambridge: Cambridge University Press. 
MacCoinnich, A. (2008). Where and how was Gaelic written in late medieval and early modern Scotland? Orthographic practices and cultural identities. Scottish Gaelic Studies, 24, 309-356.

Mills, J. (2010). Genocide and ethnocide: The suppression of the Cornish language. In J. Partridge (Ed.), Interfaces in language (pp. 189-206). Newcastle upon Tyne: Cambridge Scholars Publishing.

Parina, E. (2006). О морфологическом типе валлийского языка. In А.Б. Кошелев (Ed.), Аналитизм в языках различных типов: сорок лет спустя. К 100-летию со дня рождения В. Н. Ярцевой (pp. 236-246). Moscow: Institute of Linguistics of the Russian Academy of Sciences.

Popescu, I.-I., Altmann, G. (2008a). Hapax legomena and language typology. Journal of Quantitative Linguistics, 15(4), 370-378.

Popescu, I.-I., Altmann, G. (2008b). Zipf's mean and language typology. Glottometrics, $16,31-37$.

Popescu, I.-I., Mačutek, J. \& Altmann, G. (2009). Aspects of word frequencies. Lüdenscheid: RAM-Verlag.

Russell, P. (1995). An introduction to the Celtic languages. London: Longman.

Sapir, E. (1921). Language: An introduction to the study of speech. New York: Harcourt Brace and Company.

Sebba, M. (1998). Orthography as practice and ideology: The case of Manx. Centre for Language in Social Life Working Paper 102. Lancaster University.

Tristram, H.L.C. (2009). Wie weit sind die inselkeltischen Sprachen (und das Englische) analytisiert? In U. Hinrichs, N. Reiter \& S. Tornow (Ed.), Eurolinguistik: Entwicklung und Perspektiven (pp. 255-280). Wiesbaden: Harrassowitz. 
Tristram, H.L.C. (2010). Probleme bei der Quantifizierung morphologischer

Komplexität im Altirischen. In: K. Stüber, T. Zehnder \& D. Bachmann (Eds.), Akten des 5. Deutschsprachigen Keltologensymposiums (pp. 407-426). Vienna: Praesens Verlag.

Welch, B.L. (1947). The generalization of 'Student's' problem when several different population variances are involved. Biometrika, 34, 28-35. 


\section{Appendix 1}

Results for the individual texts. Additional abbreviations: $\mathrm{N}=$ token count; $\mathrm{V}=$ type count; $\mathrm{A}$ and $\mathrm{b}=$ parameters of the Zipfian function; $\mathrm{SG}=$ Scottish Gaelic; EMI = Early Modern Irish; PDI = Present-Day Irish.

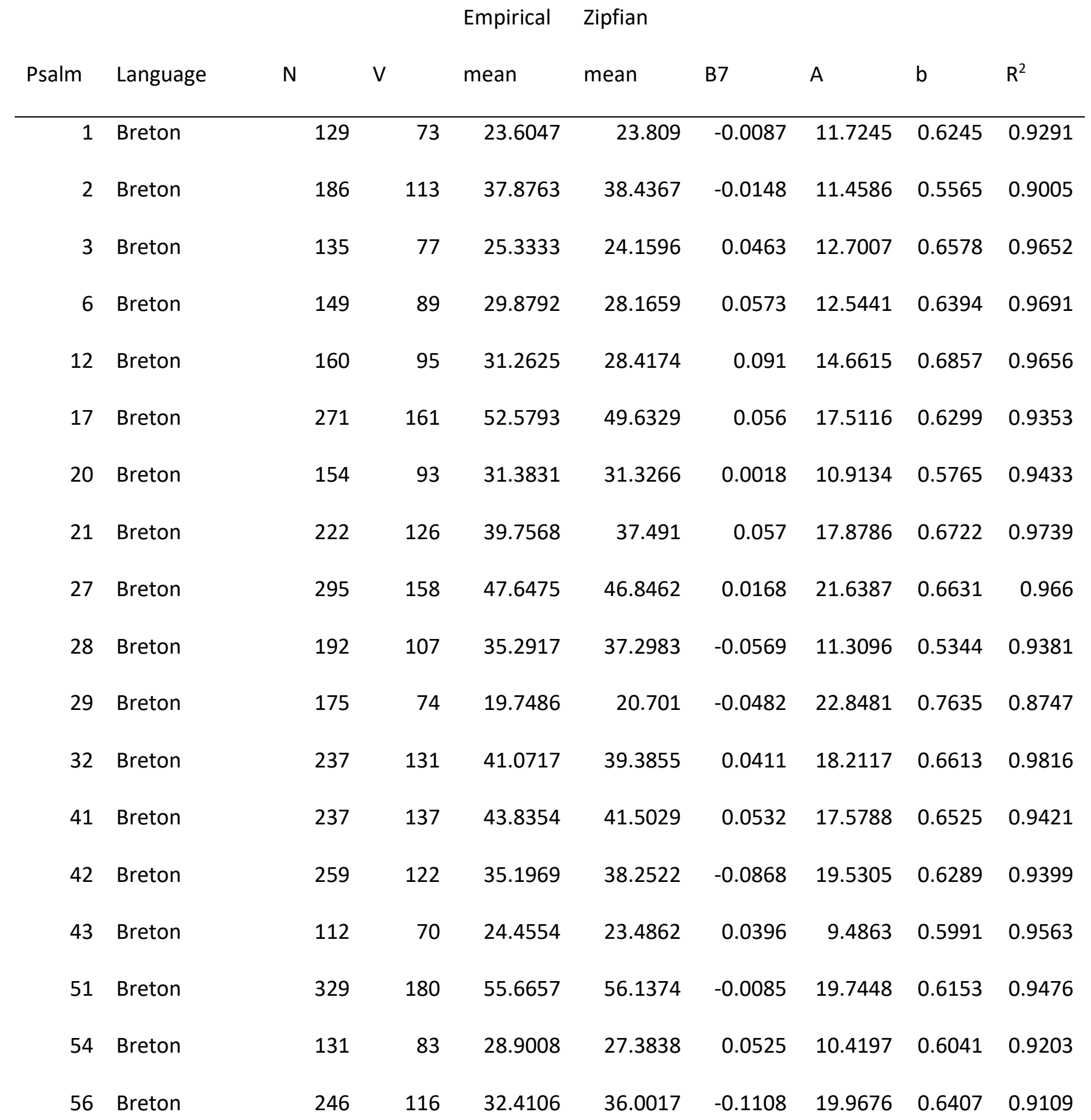




\begin{tabular}{|c|c|c|c|c|c|c|c|c|c|}
\hline 79 & Breton & 245 & 146 & 48.3918 & 42.2194 & 0.1276 & 18.5136 & 0.6873 & 0.9689 \\
\hline 81 & Breton & 267 & 153 & 48.9326 & 50.2782 & -0.0275 & 15.2755 & 0.5758 & 0.9112 \\
\hline 84 & Breton & 222 & 113 & 34.027 & 36.727 & -0.0793 & 15.8549 & 0.6002 & 0.9285 \\
\hline 85 & Breton & 218 & 111 & 33.5229 & 35.1608 & -0.0489 & 16.71 & 0.6249 & 0.9438 \\
\hline 90 & Breton & 293 & 161 & 50.1399 & 50.1517 & -0.0002 & 18.6771 & 0.621 & 0.9514 \\
\hline 91 & Breton & 256 & 143 & 44.6484 & 42.7898 & 0.0416 & 19.0799 & 0.6606 & 0.9792 \\
\hline 95 & Breton & 168 & 103 & 35.744 & 37.3533 & -0.045 & 8.9565 & 0.4943 & 0.868 \\
\hline 96 & Breton & 223 & 96 & 26.5695 & 29.4724 & -0.1093 & 20.5597 & 0.662 & 0.9281 \\
\hline 97 & Breton & 218 & 107 & 30.0413 & 29.8341 & 0.0069 & 23.0625 & 0.7358 & 0.9407 \\
\hline 98 & Breton & 163 & 83 & 25.6135 & 27.6119 & -0.078 & 13.1357 & 0.5959 & 0.9295 \\
\hline 99 & Breton & 169 & 89 & 27.8047 & 29.6589 & -0.0667 & 12.9462 & 0.5898 & 0.9328 \\
\hline 101 & Breton & 159 & 91 & 29.4025 & 28.0341 & 0.0465 & 14.2312 & 0.6626 & 0.9418 \\
\hline 1 & Cornish & 116 & 67 & 22.2931 & 21.6833 & 0.0274 & 11.0888 & 0.6389 & 0.9711 \\
\hline 2 & Cornish & 178 & 116 & 41.0337 & 37.6351 & 0.0828 & 11.8399 & 0.6005 & 0.924 \\
\hline 3 & Cornish & 124 & 70 & 23.0726 & 21.9689 & 0.0478 & 12.3175 & 0.6652 & 0.9725 \\
\hline 6 & Cornish & 149 & 88 & 28.698 & 25.5419 & 0.11 & 15.2838 & 0.7173 & 0.9407 \\
\hline 12 & Cornish & 139 & 91 & 32.3165 & 28.0932 & 0.1307 & 11.8606 & 0.6607 & 0.9394 \\
\hline 17 & Cornish & 283 & 160 & 51.3852 & 50.0227 & 0.0265 & 17.7254 & 0.6182 & 0.9605 \\
\hline 20 & Cornish & 143 & 82 & 26.9441 & 28.1485 & -0.0447 & 10.5564 & 0.5648 & 0.9086 \\
\hline 21 & Cornish & 210 & 117 & 36.9524 & 33.2225 & 0.1009 & 18.9781 & 0.7151 & 0.9767 \\
\hline 27 & Cornish & 284 & 151 & 44.8099 & 44.3078 & 0.0112 & 22.1933 & 0.6738 & 0.9473 \\
\hline 28 & Cornish & 173 & 104 & 35.4682 & 37.3333 & -0.0526 & 9.4867 & 0.5049 & 0.8971 \\
\hline 29 & Cornish & 166 & 71 & 19.1566 & 19.2205 & -0.0033 & 23.2573 & 0.7951 & 0.8869 \\
\hline 32 & Cornish & 217 & 131 & 44.2212 & 44.3349 & -0.0026 & 12.2774 & 0.5546 & 0.9239 \\
\hline 41 & Cornish & 217 & 128 & 42.1613 & 41.5036 & 0.0156 & 14.0111 & 0.5961 & 0.9602 \\
\hline 42 & Cornish & 245 & 126 & 38.7796 & 38.6326 & 0.0038 & 18.3553 & 0.6468 & 0.9725 \\
\hline
\end{tabular}




\begin{tabular}{|c|c|c|c|c|c|c|c|c|c|}
\hline 43 & Cornish & 107 & 71 & 25.6916 & 24.0604 & 0.0635 & 8.6647 & 0.5878 & 0.9383 \\
\hline 51 & Cornish & 274 & 158 & 50.9051 & 48.2274 & 0.0526 & 18.3323 & 0.6391 & 0.9431 \\
\hline 54 & Cornish & 100 & 69 & 26.13 & 24.4472 & 0.0644 & 7.2608 & 0.5421 & 0.8886 \\
\hline 56 & Cornish & 213 & 107 & 32.3944 & 33.9801 & -0.0489 & 16.5119 & 0.6247 & 0.9459 \\
\hline 79 & Cornish & 227 & 134 & 43.3524 & 42.2683 & 0.025 & 15.5716 & 0.6187 & 0.9228 \\
\hline 81 & Cornish & 244 & 145 & 47.1967 & 44.6118 & 0.0548 & 16.815 & 0.6365 & 0.9572 \\
\hline 84 & Cornish & 200 & 117 & 38.14 & 35.7851 & 0.0617 & 15.5483 & 0.653 & 0.9738 \\
\hline 85 & Cornish & 186 & 100 & 31.1505 & 29.6653 & 0.0477 & 17.1023 & 0.6893 & 0.9799 \\
\hline 90 & Cornish & 273 & 155 & 49.5934 & 49.3554 & 0.0048 & 16.7433 & 0.6036 & 0.9437 \\
\hline 91 & Cornish & 240 & 145 & 48.2083 & 46.0808 & 0.0441 & 15.0508 & 0.6083 & 0.9691 \\
\hline 95 & Cornish & 167 & 109 & 39.4611 & 39.9648 & -0.0128 & 8.1535 & 0.4797 & 0.9203 \\
\hline 96 & Cornish & 203 & 91 & 25.7438 & 26.0932 & -0.0136 & 21.5342 & 0.725 & 0.9823 \\
\hline 97 & Cornish & 178 & 101 & 31.4157 & 27.9735 & 0.1096 & 18.7429 & 0.7454 & 0.9653 \\
\hline 98 & Cornish & 143 & 80 & 25.9091 & 24.2658 & 0.0634 & 14.0359 & 0.6861 & 0.9662 \\
\hline 99 & Cornish & 159 & 74 & 21.7358 & 24.0197 & -0.1051 & 14.7507 & 0.6282 & 0.9371 \\
\hline 101 & Cornish & 147 & 86 & 28.4898 & 25.4314 & 0.1073 & 14.3295 & 0.703 & 0.9442 \\
\hline 1 & EMI & 120 & 78 & 27.4917 & 25.451 & 0.0742 & 10.1514 & 0.6193 & 0.9213 \\
\hline 2 & EMI & 185 & 127 & 43.8731 & 39.0871 & 0.1091 & 14.2126 & 0.643 & 0.9647 \\
\hline 3 & EMI & 116 & 90 & 31.9286 & 29.7209 & 0.0691 & 10.3711 & 0.5981 & 0.9619 \\
\hline 6 & EMI & 163 & 95 & 34.4028 & 33.9978 & 0.0118 & 8.3477 & 0.5126 & 0.9008 \\
\hline 12 & EMI & 144 & 93 & 33.6357 & 31.7986 & 0.0546 & 9.3176 & 0.5615 & 0.9522 \\
\hline 17 & EMI & 264 & 182 & 63.6117 & 53.5673 & 0.1579 & 17.7982 & 0.6623 & 0.9522 \\
\hline 20 & EMI & 150 & 88 & 30.7111 & 27.4659 & 0.1057 & 11.7503 & 0.653 & 0.94 \\
\hline 21 & EMI & 214 & 135 & 44.8157 & 35.6894 & 0.2036 & 20.3396 & 0.7607 & 0.9653 \\
\hline 27 & EMI & 298 & 167 & 51.6782 & 46.6207 & 0.0979 & 23.5221 & 0.7074 & 0.943 \\
\hline 28 & EMI & 183 & 109 & 36.0865 & 34.0214 & 0.0572 & 14.2824 & 0.6393 & 0.9746 \\
\hline
\end{tabular}




\begin{tabular}{|c|c|c|c|c|c|c|c|c|c|}
\hline 29 & EMI & 158 & 75 & 21.0188 & 20.8614 & 0.0075 & 20.5082 & 0.767 & 0.9397 \\
\hline 32 & EMI & 219 & 140 & 46.7424 & 41.8068 & 0.1056 & 16.81 & 0.6634 & 0.9751 \\
\hline 41 & EMI & 237 & 147 & 49.8584 & 45.5977 & 0.0855 & 15.3294 & 0.6289 & 0.9621 \\
\hline 42 & EMI & 269 & 140 & 44.94 & 47.1879 & -0.05 & 13.9402 & 0.5557 & 0.9244 \\
\hline 43 & EMI & 128 & 73 & 25.8462 & 25.7246 & 0.0047 & 8.4681 & 0.5444 & 0.9574 \\
\hline 51 & EMI & 308 & 166 & 51.4812 & 45.9588 & 0.1073 & 24.0275 & 0.714 & 0.9243 \\
\hline 54 & EMI & 107 & 76 & 30.402 & 29.3711 & 0.0339 & 5.2787 & 0.4353 & 0.9106 \\
\hline 56 & EMI & 230 & 115 & 36.3785 & 33.8679 & 0.069 & 18.0838 & 0.6863 & 0.9769 \\
\hline 79 & EMI & 283 & 154 & 51.9212 & 44.1909 & 0.1489 & 18.6139 & 0.6905 & 0.9001 \\
\hline 81 & EMI & 253 & 154 & 51.172 & 44.1684 & 0.1369 & 18.9872 & 0.6909 & 0.9752 \\
\hline 84 & EMI & 227 & 126 & 40.9437 & 34.3537 & 0.161 & 19.631 & 0.7421 & 0.9709 \\
\hline 85 & EMI & 197 & 123 & 42.0105 & 34.1684 & 0.1867 & 17.1955 & 0.7292 & 0.9552 \\
\hline 90 & EMI & 278 & 177 & 59.2384 & 51.5155 & 0.1304 & 19.5207 & 0.6724 & 0.9264 \\
\hline 91 & EMI & 271 & 149 & 48.812 & 45.8052 & 0.0616 & 16.9061 & 0.6359 & 0.9543 \\
\hline 95 & EMI & 191 & 116 & 41.2543 & 36.7379 & 0.1095 & 12.2866 & 0.6227 & 0.9296 \\
\hline 96 & EMI & 213 & 111 & 32.977 & 31.9019 & 0.0326 & 20.4953 & 0.7088 & 0.9659 \\
\hline 97 & EMI & 192 & 122 & 40.145 & 34.9525 & 0.1293 & 17.5312 & 0.7052 & 0.9421 \\
\hline 98 & EMI & 137 & 93 & 30.0127 & 27.0464 & 0.0988 & 15.7475 & 0.7114 & 0.9574 \\
\hline 99 & EMI & 187 & 95 & 31.1779 & 30.4035 & 0.0248 & 13.0273 & 0.6247 & 0.9599 \\
\hline 101 & EMI & 152 & 102 & 36.7582 & 34.5933 & 0.0589 & 9.8466 & 0.5646 & 0.9204 \\
\hline 1 & Manx & 120 & 83 & 28.9248 & 28.6715 & 0.0088 & 9.416 & 0.5575 & 0.9146 \\
\hline 2 & Manx & 197 & 141 & 49.0541 & 47.7106 & 0.0274 & 11.8863 & 0.5516 & 0.9348 \\
\hline 3 & Manx & 140 & 82 & 28.5267 & 28.7141 & -0.0066 & 9.0552 & 0.5439 & 0.8673 \\
\hline 6 & Manx & 144 & 100 & 33.6325 & 33.1638 & 0.0139 & 11.7001 & 0.5877 & 0.9501 \\
\hline 12 & Manx & 140 & 111 & 38.3352 & 38.7999 & -0.0121 & 10.1871 & 0.5298 & 0.9077 \\
\hline 17 & Manx & 273 & 182 & 56.6163 & 58.1746 & -0.0275 & 18.5796 & 0.5936 & 0.9248 \\
\hline
\end{tabular}




\begin{tabular}{|c|c|c|c|c|c|c|c|c|c|}
\hline 20 & Manx & 135 & 94 & 30.2061 & 30.0159 & 0.0063 & 13.4771 & 0.6275 & 0.9451 \\
\hline 21 & Manx & 217 & 136 & 42.0729 & 43.6714 & -0.038 & 16.234 & 0.602 & 0.9273 \\
\hline 27 & Manx & 289 & 167 & 47.8537 & 48.0645 & -0.0044 & 25.8592 & 0.684 & 0.9737 \\
\hline 28 & Manx & 185 & 119 & 38.296 & 41.7763 & -0.0909 & 12.1116 & 0.5222 & 0.9266 \\
\hline 29 & Manx & 160 & 91 & 26.2162 & 25.6813 & 0.0204 & 20.5093 & 0.7382 & 0.9567 \\
\hline 32 & Manx & 229 & 141 & 46.214 & 47.0238 & -0.0175 & 13.7863 & 0.5654 & 0.9441 \\
\hline 41 & Manx & 233 & 136 & 41.4008 & 43.0355 & -0.0395 & 17.8125 & 0.6152 & 0.9564 \\
\hline 42 & Manx & 250 & 154 & 46.8904 & 48.9881 & -0.0447 & 18.2587 & 0.6048 & 0.9254 \\
\hline 43 & Manx & 117 & 76 & 24.7941 & 24.5805 & 0.0086 & 12.1361 & 0.6298 & 0.9544 \\
\hline 51 & Manx & 293 & 168 & 51.4121 & 52.231 & -0.0159 & 19.6208 & 0.6208 & 0.9646 \\
\hline 54 & Manx & 102 & 76 & 28.3636 & 25.6501 & 0.0957 & 8.4941 & 0.5872 & 0.9455 \\
\hline 56 & Manx & 214 & 135 & 42.747 & 43.7167 & -0.0227 & 15.7466 & 0.5947 & 0.9636 \\
\hline 79 & Manx & 241 & 160 & 49.2199 & 48.3024 & 0.0186 & 20.2323 & 0.6477 & 0.9457 \\
\hline 81 & Manx & 250 & 163 & 50.8783 & 53.4481 & -0.0505 & 16.8501 & 0.5752 & 0.9185 \\
\hline 84 & Manx & 213 & 139 & 45.5277 & 46.8552 & -0.0292 & 13.1654 & 0.5559 & 0.8966 \\
\hline 85 & Manx & 190 & 118 & 37.9766 & 38.5278 & -0.0145 & 14.3675 & 0.5937 & 0.9305 \\
\hline 90 & Manx & 281 & 172 & 50.2399 & 54.9083 & -0.0929 & 20.3717 & 0.597 & 0.9232 \\
\hline 91 & Manx & 250 & 154 & 48.2708 & 50.5495 & -0.0472 & 15.9428 & 0.5765 & 0.9057 \\
\hline 95 & Manx & 173 & 118 & 38.6049 & 38.3406 & 0.0068 & 13.8312 & 0.5983 & 0.9426 \\
\hline 96 & Manx & 217 & 112 & 32.1351 & 36.6628 & -0.1409 & 18.4786 & 0.594 & 0.9002 \\
\hline 97 & Manx & 200 & 135 & 45.4163 & 45.3672 & 0.0011 & 12.5914 & 0.5601 & 0.9033 \\
\hline 98 & Manx & 158 & 97 & 30.4611 & 31.3586 & -0.0295 & 14.0262 & 0.6139 & 0.9609 \\
\hline 99 & Manx & 163 & 103 & 34.5287 & 34.8352 & -0.0089 & 11.4491 & 0.5668 & 0.9444 \\
\hline 101 & Manx & 153 & 97 & 35.0667 & 35.6832 & -0.0176 & 7.8728 & 0.4812 & 0.8716 \\
\hline 1 & PDI & 121 & 75 & 25.9083 & 23.7424 & 0.0836 & 11.0852 & 0.6514 & 0.9663 \\
\hline 2 & PDI & 173 & 124 & 44.1351 & 39.7628 & 0.0991 & 12.1993 & 0.6078 & 0.9537 \\
\hline
\end{tabular}




\begin{tabular}{|c|c|c|c|c|c|c|c|c|c|}
\hline 3 & PDI & 113 & 80 & 29.6552 & 26.9783 & 0.0903 & 8.7171 & 0.5846 & 0.9501 \\
\hline 6 & PDI & 137 & 104 & 36.5153 & 35.6416 & 0.0239 & 10.1116 & 0.5531 & 0.9468 \\
\hline 12 & PDI & 132 & 98 & 36.0347 & 33.7996 & 0.062 & 8.9931 & 0.5498 & 0.9521 \\
\hline 17 & PDI & 256 & 165 & 54.678 & 47.3834 & 0.1334 & 19.5426 & 0.6863 & 0.9641 \\
\hline 20 & PDI & 128 & 94 & 32.1067 & 26.8584 & 0.1635 & 14.6181 & 0.7254 & 0.9533 \\
\hline 21 & PDI & 201 & 128 & 41.1542 & 38.5484 & 0.0633 & 16.9515 & 0.6612 & 0.8927 \\
\hline 27 & PDI & 280 & 158 & 47.2718 & 48.4723 & -0.0254 & 20.5195 & 0.6349 & 0.9162 \\
\hline 28 & PDI & 177 & 111 & 37.3224 & 35.1309 & 0.0587 & 13.4509 & 0.6257 & 0.9632 \\
\hline 29 & PDI & 157 & 78 & 23.0506 & 22.7778 & 0.0118 & 17.6599 & 0.7219 & 0.9425 \\
\hline 32 & PDI & 200 & 142 & 50.0091 & 46.9796 & 0.0606 & 12.3454 & 0.5727 & 0.9332 \\
\hline 41 & PDI & 218 & 147 & 49.9536 & 46.7582 & 0.064 & 14.4916 & 0.6069 & 0.9461 \\
\hline 42 & PDI & 235 & 134 & 41.0743 & 42.5773 & -0.0366 & 17.9662 & 0.6123 & 0.9774 \\
\hline 43 & PDI & 103 & 71 & 22.8672 & 24.3938 & -0.0668 & 10.4703 & 0.5734 & 0.8592 \\
\hline 51 & PDI & 277 & 158 & 46.2208 & 48.0826 & -0.0403 & 21.7393 & 0.6416 & 0.9185 \\
\hline 54 & PDI & 96 & 77 & 29.8598 & 29.4647 & 0.0132 & 5.7234 & 0.4467 & 0.8794 \\
\hline 56 & PDI & 195 & 125 & 40.2304 & 39.4378 & 0.0197 & 15.993 & 0.6221 & 0.9738 \\
\hline 79 & PDI & 229 & 178 & 59.424 & 54.4753 & 0.0833 & 17.6451 & 0.6316 & 0.9268 \\
\hline 81 & PDI & 225 & 161 & 55.2292 & 52.1394 & 0.0559 & 14.1644 & 0.5869 & 0.9579 \\
\hline 84 & PDI & 195 & 131 & 42.5595 & 40.4282 & 0.0501 & 16.1574 & 0.639 & 0.9703 \\
\hline 85 & PDI & 170 & 118 & 38.3198 & 35.2929 & 0.079 & 16.3646 & 0.6717 & 0.9213 \\
\hline 90 & PDI & 274 & 169 & 55.9964 & 54.0244 & 0.0352 & 15.9256 & 0.5965 & 0.9318 \\
\hline 91 & PDI & 243 & 151 & 46.4797 & 44.5739 & 0.041 & 20.3194 & 0.6689 & 0.942 \\
\hline 95 & PDI & 160 & 116 & 39.1937 & 38.8601 & 0.0085 & 11.9851 & 0.5701 & 0.9309 \\
\hline 96 & PDI & 195 & 106 & 31.3286 & 34.567 & -0.1034 & 15.8832 & 0.6006 & 0.8739 \\
\hline 97 & PDI & 184 & 121 & 40.7708 & 37.8354 & 0.072 & 14.102 & 0.6318 & 0.9037 \\
\hline 98 & PDI & 130 & 83 & 27.8029 & 26.0659 & 0.0625 & 12.306 & 0.6514 & 0.9465 \\
\hline
\end{tabular}




\begin{tabular}{|c|c|c|c|c|c|c|c|c|c|}
\hline 99 & PDI & 150 & 94 & 27.9947 & 30.3782 & -0.0851 & 15.1899 & 0.6162 & 0.9237 \\
\hline 101 & PDI & 142 & 97 & 34.1118 & 32.9433 & 0.0343 & 10.1405 & 0.5659 & 0.9159 \\
\hline 1 & SG & 133 & 87 & 29.6014 & 29.1797 & 0.0142 & 10.6451 & 0.5848 & 0.9539 \\
\hline 2 & SG & 222 & 136 & 47.7129 & 45.5859 & 0.0446 & 11.7351 & 0.5622 & 0.9242 \\
\hline 3 & SG & 131 & 92 & 33.0567 & 33.6458 & -0.0178 & 7.8505 & 0.4904 & 0.8742 \\
\hline 6 & SG & 166 & 107 & 35.5337 & 35.6194 & -0.0024 & 12.0152 & 0.5804 & 0.9156 \\
\hline 12 & SG & 179 & 115 & 40.0279 & 39.6622 & 0.0091 & 10.3842 & 0.5418 & 0.8829 \\
\hline 17 & SG & 331 & 202 & 65.5616 & 62.4483 & 0.0475 & 19.1459 & 0.618 & 0.92 \\
\hline 20 & SG & 165 & 97 & 31.5629 & 32.8242 & -0.04 & 11.6063 & 0.5696 & 0.8805 \\
\hline 21 & SG & 247 & 132 & 41.3882 & 40.6993 & 0.0166 & 17.3123 & 0.6394 & 0.9645 \\
\hline 27 & SG & 335 & 183 & 57.7757 & 56.0704 & 0.0295 & 19.864 & 0.6294 & 0.9421 \\
\hline 28 & SG & 223 & 126 & 41.1081 & 42.9998 & -0.046 & 12.692 & 0.5481 & 0.914 \\
\hline 29 & SG & 185 & 93 & 28.8857 & 29.942 & -0.0366 & 14.2945 & 0.6204 & 0.9139 \\
\hline 32 & SG & 243 & 146 & 48.5436 & 49.3443 & -0.0165 & 12.9448 & 0.5513 & 0.8963 \\
\hline 41 & SG & 262 & 145 & 45.0736 & 43.9741 & 0.0244 & 18.8046 & 0.6487 & 0.9414 \\
\hline 42 & SG & 292 & 161 & 48.637 & 49.2926 & -0.0135 & 20.4672 & 0.6357 & 0.9457 \\
\hline 43 & SG & 136 & 81 & 26.6667 & 27.0127 & -0.013 & 11.2262 & 0.5951 & 0.9412 \\
\hline 51 & SG & 313 & 177 & 54.5906 & 53.6156 & 0.0179 & 20.8221 & 0.6403 & 0.9672 \\
\hline 54 & SG & 110 & 79 & 31.4667 & 30.1031 & 0.0433 & 5.5551 & 0.4504 & 0.881 \\
\hline 56 & SG & 249 & 136 & 43.132 & 46.7051 & -0.0828 & 13.4581 & 0.5387 & 0.9154 \\
\hline 79 & SG & 291 & 167 & 53.3808 & 52.7373 & 0.0121 & 17.2506 & 0.6077 & 0.8514 \\
\hline 81 & SG & 304 & 163 & 53.7582 & 53.5838 & 0.0032 & 14.8334 & 0.5729 & 0.9239 \\
\hline 84 & SG & 235 & 139 & 44.15 & 47.0593 & -0.0659 & 14.3189 & 0.5517 & 0.9442 \\
\hline 85 & SG & 214 & 116 & 38.8731 & 37.5297 & 0.0346 & 13.4624 & 0.6031 & 0.9461 \\
\hline 90 & SG & 346 & 193 & 60.608 & 63.8534 & -0.0535 & 17.1988 & 0.5608 & 0.9391 \\
\hline 91 & SG & 277 & 164 & 53.1053 & 54.1176 & -0.0191 & 15.355 & 0.5691 & 0.9143 \\
\hline
\end{tabular}




\begin{tabular}{|c|c|c|c|c|c|c|c|c|c|}
\hline 95 & SG & 205 & 118 & 39.9792 & 37.4329 & 0.0637 & 13.5585 & 0.6202 & 0.9616 \\
\hline 96 & SG & 259 & 126 & 37.8538 & 40.7864 & -0.0775 & 17.0563 & 0.5984 & 0.9392 \\
\hline 97 & SG & 221 & 131 & 43.8356 & 43.1113 & 0.0165 & 13.3919 & 0.5812 & 0.9268 \\
\hline 98 & SG & 180 & 96 & 31.4061 & 31.3962 & 0.0003 & 12.4896 & 0.6036 & 0.9447 \\
\hline 99 & SG & 174 & 96 & 30.3807 & 31.8112 & -0.0471 & 13.0049 & 0.5909 & 0.9289 \\
\hline 101 & SG & 150 & 113 & 40.3636 & 40.0049 & 0.0089 & 9.3643 & 0.5158 & 0.9545 \\
\hline 1 & Welsh & 143 & 73 & 24.5372 & 24.2163 & 0.0131 & 10.4558 & 0.6076 & 0.9259 \\
\hline 2 & Welsh & 209 & 117 & 42.052 & 37.8067 & 0.101 & 11.5527 & 0.6038 & 0.9494 \\
\hline 3 & Welsh & 141 & 71 & 25.5575 & 26.2295 & -0.0263 & 7.2747 & 0.493 & 0.9155 \\
\hline 6 & Welsh & 178 & 84 & 27.9781 & 26.0409 & 0.0692 & 12.7139 & 0.6625 & 0.926 \\
\hline 12 & Welsh & 179 & 89 & 32.2652 & 28.4983 & 0.1167 & 10.5232 & 0.6284 & 0.9494 \\
\hline 17 & Welsh & 333 & 165 & 56.3203 & 52.8944 & 0.0608 & 14.7388 & 0.595 & 0.8993 \\
\hline 20 & Welsh & 167 & 79 & 27.2969 & 26.0932 & 0.0441 & 10.4028 & 0.6064 & 0.9337 \\
\hline 21 & Welsh & 237 & 120 & 39.4229 & 38.3144 & 0.0281 & 14.1349 & 0.6135 & 0.9413 \\
\hline 27 & Welsh & 321 & 150 & 45.4286 & 46.1904 & -0.0168 & 19.3857 & 0.6341 & 0.9535 \\
\hline 28 & Welsh & 222 & 113 & 39.6271 & 39.3573 & 0.0068 & 10.021 & 0.5326 & 0.9144 \\
\hline 29 & Welsh & 175 & 72 & 20.2102 & 20.3132 & -0.0051 & 19.9926 & 0.7589 & 0.946 \\
\hline 32 & Welsh & 241 & 133 & 46.86 & 42.5762 & 0.0914 & 12.8767 & 0.6059 & 0.9082 \\
\hline 41 & Welsh & 258 & 131 & 43.2569 & 42.9338 & 0.0075 & 13.5891 & 0.5851 & 0.9347 \\
\hline 42 & Welsh & 303 & 130 & 41.8468 & 42.1961 & -0.0083 & 15.0189 & 0.5944 & 0.9656 \\
\hline 43 & Welsh & 141 & 71 & 26.6893 & 25.951 & 0.0277 & 6.7763 & 0.5054 & 0.9098 \\
\hline 51 & Welsh & 320 & 162 & 51.6209 & 51.1832 & 0.0085 & 17.1309 & 0.6085 & 0.9085 \\
\hline 54 & Welsh & 105 & 65 & 24.1771 & 23.4394 & 0.0305 & 7.0092 & 0.5265 & 0.9084 \\
\hline 56 & Welsh & 250 & 109 & 35.3744 & 34.9436 & 0.0122 & 14.2662 & 0.615 & 0.9426 \\
\hline 79 & Welsh & 281 & 145 & 49.2576 & 43.8355 & 0.1101 & 16.1072 & 0.6514 & 0.9498 \\
\hline 81 & Welsh & 273 & 145 & 50.52 & 49.1284 & 0.0275 & 11.8244 & 0.5492 & 0.9253 \\
\hline
\end{tabular}




\begin{tabular}{|c|c|c|c|c|c|c|c|c|c|}
\hline 84 & Welsh & 260 & 123 & 41.8103 & 39.6058 & 0.0527 & 13.1339 & 0.6045 & 0.9159 \\
\hline 85 & Welsh & 197 & 111 & 39.2824 & 31.4756 & 0.1987 & 14.9019 & 0.7197 & 0.9261 \\
\hline 90 & Welsh & 352 & 156 & 48.1642 & 43.6084 & 0.0946 & 22.792 & 0.7101 & 0.9503 \\
\hline 91 & Welsh & 285 & 139 & 44.0082 & 41.962 & 0.0465 & 17.975 & 0.6547 & 0.9674 \\
\hline 95 & Welsh & 192 & 107 & 38.5125 & 36.2953 & 0.0576 & 10.0044 & 0.5619 & 0.9259 \\
\hline 96 & Welsh & 253 & 100 & 30.6103 & 33.1476 & -0.0829 & 14.2133 & 0.5882 & 0.9074 \\
\hline 97 & Welsh & 219 & 100 & 30.2391 & 28.3064 & 0.0639 & 18.8872 & 0.7285 & 0.9576 \\
\hline 98 & Welsh & 165 & 82 & 28.9385 & 27.9046 & 0.0357 & 9.5572 & 0.5738 & 0.9594 \\
\hline 99 & Welsh & 176 & 86 & 28.34 & 29.7445 & -0.0496 & 10.5008 & 0.5541 & 0.9086 \\
\hline 101 & Welsh & 176 & 90 & 31.9085 & 32.3559 & -0.014 & 8.4681 & 0.5104 & 0.8996 \\
\hline
\end{tabular}




\section{Appendix 2}

Token-Type Ratio (TTR) for each psalm in each language. Abbreviated labels: $\mathrm{ScotG}=$ Scottish Gaelic, PDI = Present-Day Irish, EMI = Early Modern Irish.

\begin{tabular}{|c|c|c|}
\hline Psalm & Language & TTR \\
\hline 1 & Breton & 1.7671 \\
\hline 2 & Breton & 1.646 \\
\hline 3 & Breton & 1.7532 \\
\hline 6 & Breton & 1.6742 \\
\hline 12 & Breton & 1.6842 \\
\hline 17 & Breton & 1.6832 \\
\hline 20 & Breton & 1.6559 \\
\hline 21 & Breton & 1.7619 \\
\hline 27 & Breton & 1.8671 \\
\hline 28 & Breton & 1.7944 \\
\hline 29 & Breton & 2.3649 \\
\hline 32 & Breton & 1.8092 \\
\hline 41 & Breton & 1.7299 \\
\hline 42 & Breton & 2.123 \\
\hline 43 & Breton & 1.6 \\
\hline 51 & Breton & 1.8278 \\
\hline 54 & Breton & 1.5783 \\
\hline 56 & Breton & 2.1207 \\
\hline 79 & Breton & 1.6781 \\
\hline 81 & Breton & 1.7451 \\
\hline
\end{tabular}




\begin{tabular}{|c|c|c|}
\hline 84 & Breton & 1.9646 \\
\hline 85 & Breton & 1.964 \\
\hline 90 & Breton & 1.8199 \\
\hline 91 & Breton & 1.7902 \\
\hline 95 & Breton & 1.6311 \\
\hline 96 & Breton & 2.3229 \\
\hline 97 & Breton & 2.0374 \\
\hline 98 & Breton & 1.9639 \\
\hline 99 & Breton & 1.8989 \\
\hline 101 & Breton & 1.7473 \\
\hline 1 & Cornish & 1.7313 \\
\hline 2 & Cornish & 1.5345 \\
\hline 3 & Cornish & 1.7714 \\
\hline 6 & Cornish & 1.6932 \\
\hline 12 & Cornish & 1.5275 \\
\hline 17 & Cornish & 1.7688 \\
\hline 20 & Cornish & 1.7439 \\
\hline 21 & Cornish & 1.7949 \\
\hline 27 & Cornish & 1.8808 \\
\hline 28 & Cornish & 1.6635 \\
\hline 29 & Cornish & 2.338 \\
\hline 32 & Cornish & 1.6565 \\
\hline 41 & Cornish & 1.6953 \\
\hline 42 & Cornish & 1.9444 \\
\hline
\end{tabular}




\begin{tabular}{|c|c|c|}
\hline 43 & Cornish & 1.507 \\
\hline 51 & Cornish & 1.7342 \\
\hline 54 & Cornish & 1.4493 \\
\hline 56 & Cornish & 1.9907 \\
\hline 79 & Cornish & 1.694 \\
\hline 81 & Cornish & 1.6828 \\
\hline 84 & Cornish & 1.7094 \\
\hline 85 & Cornish & 1.86 \\
\hline 90 & Cornish & 1.7613 \\
\hline 91 & Cornish & 1.6552 \\
\hline 95 & Cornish & 1.5321 \\
\hline 96 & Cornish & 2.2308 \\
\hline 97 & Cornish & 1.7624 \\
\hline 98 & Cornish & 1.7875 \\
\hline 99 & Cornish & 2.1486 \\
\hline 101 & Cornish & 1.7093 \\
\hline 1 & EMI & 1.5385 \\
\hline 2 & EMI & 1.4567 \\
\hline 3 & EMI & 1.2889 \\
\hline 6 & EMI & 1.7158 \\
\hline 12 & EMI & 1.5484 \\
\hline 17 & EMI & 1.4505 \\
\hline 20 & EMI & 1.7045 \\
\hline 21 & EMI & 1.5852 \\
\hline
\end{tabular}




\begin{tabular}{|c|c|c|}
\hline 27 & EMI & 1.7844 \\
\hline 28 & EMI & 1.6789 \\
\hline 29 & EMI & 2.1067 \\
\hline 32 & EMI & 1.5643 \\
\hline 41 & EMI & 1.6122 \\
\hline 42 & EMI & 1.9214 \\
\hline 43 & EMI & 1.7534 \\
\hline 51 & EMI & 1.8554 \\
\hline 54 & EMI & 1.4079 \\
\hline 56 & EMI & 2 \\
\hline 79 & EMI & 1.8377 \\
\hline 81 & EMI & 1.6429 \\
\hline 84 & EMI & 1.8016 \\
\hline 85 & EMI & 1.6016 \\
\hline 90 & EMI & 1.5706 \\
\hline 91 & EMI & 1.8188 \\
\hline 95 & EMI & 1.6466 \\
\hline 96 & EMI & 1.9189 \\
\hline 97 & EMI & 1.5738 \\
\hline 98 & EMI & 1.4731 \\
\hline 99 & EMI & 1.9684 \\
\hline 101 & EMI & 1.4902 \\
\hline 1 & Manx & 1.4458 \\
\hline 2 & Manx & 1.3972 \\
\hline
\end{tabular}




\begin{tabular}{|c|c|c|}
\hline 3 & Manx & 1.7073 \\
\hline 6 & Manx & 1.44 \\
\hline 12 & $\operatorname{Man} x$ & 1.2613 \\
\hline 17 & Manx & 1.5 \\
\hline 20 & Manx & 1.4362 \\
\hline 21 & Manx & 1.5956 \\
\hline 27 & Manx & 1.7305 \\
\hline 28 & Manx & 1.5546 \\
\hline 29 & Manx & 1.7582 \\
\hline 32 & Manx & 1.6241 \\
\hline 41 & Manx & 1.7132 \\
\hline 42 & Manx & 1.6234 \\
\hline 43 & Manx & 1.5395 \\
\hline 51 & Manx & 1.744 \\
\hline 54 & Manx & 1.3421 \\
\hline 56 & Manx & 1.5852 \\
\hline 79 & Manx & 1.5063 \\
\hline 81 & Manx & 1.5337 \\
\hline 84 & Manx & 1.5324 \\
\hline 85 & Manx & 1.6102 \\
\hline 90 & Manx & 1.6337 \\
\hline 91 & Manx & 1.6234 \\
\hline 95 & Manx & 1.4661 \\
\hline 96 & $\operatorname{Man} x$ & 1.9375 \\
\hline
\end{tabular}




\begin{tabular}{|c|c|c|}
\hline 97 & Manx & 1.4815 \\
\hline 98 & Manx & 1.6289 \\
\hline 99 & Manx & 1.5825 \\
\hline 101 & Manx & 1.5773 \\
\hline 1 & PDI & 1.6133 \\
\hline 2 & PDI & 1.3952 \\
\hline 3 & PDI & 1.4125 \\
\hline 6 & PDI & 1.3173 \\
\hline 12 & PDI & 1.3469 \\
\hline 17 & PDI & 1.5515 \\
\hline 20 & PDI & 1.3617 \\
\hline 21 & PDI & 1.5703 \\
\hline 27 & PDI & 1.7722 \\
\hline 28 & PDI & 1.5946 \\
\hline 29 & PDI & 2.0128 \\
\hline 32 & PDI & 1.4085 \\
\hline 41 & PDI & 1.483 \\
\hline 42 & PDI & 1.7537 \\
\hline 43 & PDI & 1.4507 \\
\hline 51 & PDI & 1.7532 \\
\hline 54 & PDI & 1.2468 \\
\hline 56 & PDI & 1.56 \\
\hline 79 & PDI & 1.2865 \\
\hline 81 & PDI & 1.3975 \\
\hline
\end{tabular}




\begin{tabular}{|c|c|c|}
\hline 84 & PDI & 1.4885 \\
\hline 85 & PDI & 1.4407 \\
\hline 90 & PDI & 1.6213 \\
\hline 91 & PDI & 1.6093 \\
\hline 95 & PDI & 1.3793 \\
\hline 96 & PDI & 1.8396 \\
\hline 97 & PDI & 1.5207 \\
\hline 98 & PDI & 1.5663 \\
\hline 99 & PDI & 1.5957 \\
\hline 101 & PDI & 1.4639 \\
\hline 1 & $S \cot G$ & 1.5287 \\
\hline 2 & $S \cot G$ & 1.6324 \\
\hline 3 & $S \cot G$ & 1.4239 \\
\hline 6 & $S \cot G$ & 1.5514 \\
\hline 12 & ScotG & 1.5565 \\
\hline 17 & $S \cot G$ & 1.6386 \\
\hline 20 & $S \cot G$ & 1.701 \\
\hline 21 & $S \cot G$ & 1.8712 \\
\hline 27 & $S \cot G$ & 1.8306 \\
\hline 28 & $S \cot G$ & 1.7698 \\
\hline 29 & $\mathrm{Scot} G$ & 1.9892 \\
\hline 32 & $S \cot G$ & 1.6644 \\
\hline 41 & $S \cot G$ & 1.8069 \\
\hline 42 & $S \cot G$ & 1.8137 \\
\hline
\end{tabular}




\begin{tabular}{|c|c|c|}
\hline 43 & $\mathrm{Scot} G$ & 1.679 \\
\hline 51 & $S \cot G$ & 1.7684 \\
\hline 54 & $S \cot G$ & 1.3924 \\
\hline 56 & $S \cot G$ & 1.8309 \\
\hline 79 & $\mathrm{Scot} G$ & 1.7425 \\
\hline 81 & $S \cot G$ & 1.865 \\
\hline 84 & $S \cot G$ & 1.6906 \\
\hline 85 & $S \cot G$ & 1.8448 \\
\hline 90 & $\mathrm{Scot} G$ & 1.7927 \\
\hline 91 & $S \cot G$ & 1.689 \\
\hline 95 & $S \cot G$ & 1.7373 \\
\hline 96 & $S \cot G$ & 2.0556 \\
\hline 97 & $S \cot G$ & 1.687 \\
\hline 98 & $S \cot G$ & 1.875 \\
\hline 99 & $S \cot G$ & 1.8125 \\
\hline 101 & $S \cot G$ & 1.3274 \\
\hline 1 & Welsh & 1.9589 \\
\hline 2 & Welsh & 1.7863 \\
\hline 3 & Welsh & 1.9859 \\
\hline 6 & Welsh & 2.119 \\
\hline 12 & Welsh & 2.0112 \\
\hline 17 & Welsh & 2.0182 \\
\hline 20 & Welsh & 2.1139 \\
\hline 21 & Welsh & 1.975 \\
\hline
\end{tabular}




\begin{tabular}{|c|c|c|}
\hline 27 & Welsh & 2.14 \\
\hline 28 & Welsh & 1.9646 \\
\hline 29 & Welsh & 2.4306 \\
\hline 32 & Welsh & 1.812 \\
\hline 41 & Welsh & 1.9695 \\
\hline 42 & Welsh & 2.3308 \\
\hline 43 & Welsh & 1.9859 \\
\hline 51 & Welsh & 1.9753 \\
\hline 54 & Welsh & 1.6154 \\
\hline 56 & Welsh & 2.2936 \\
\hline 79 & Welsh & 1.9379 \\
\hline 81 & Welsh & 1.8828 \\
\hline 84 & Welsh & 2.1138 \\
\hline 85 & Welsh & 1.7748 \\
\hline 90 & Welsh & 2.2564 \\
\hline 91 & Welsh & 2.0504 \\
\hline 95 & Welsh & 1.7944 \\
\hline 96 & Welsh & 2.53 \\
\hline 97 & Welsh & 2.19 \\
\hline 98 & Welsh & 2.0122 \\
\hline 99 & Welsh & 2.0465 \\
\hline 101 & Welsh & 1.9556 \\
\hline
\end{tabular}



Table 1. Mean values, standard deviations, and 95\% CIs for indicator B7.

\begin{tabular}{|l|l|l|l|l|}
\hline Language & Mean B7 & SD & $95 \%$ Lower CI & $95 \%$ Upper CI \\
\hline Early Modern Irish & 0.0861 & 0.0580 & 0.0645 & 0.1078 \\
\hline Present-Day Irish & 0.0370 & 0.0607 & 0.0144 & 0.0597 \\
\hline Welsh & 0.0367 & 0.0559 & 0.0159 & 0.0576 \\
\hline Cornish & 0.0324 & 0.0550 & 0.0119 & 0.0529 \\
\hline Breton & -0.0018 & 0.0613 & -0.0247 & 0.0211 \\
\hline Scottish Gaelic & -0.0048 & 0.0424 & -0.0191 & 0.0094 \\
\hline Manx & -0.0181 & 0.0381 & -0.0339 & -0.0023 \\
\hline
\end{tabular}


Table 2. 99.7619\% Welch-Satterthwaite confidence intervals for differences in mean B7 between pairs of languages. Abbreviated labels: $\mathrm{ScotG}=\mathrm{Scottish}$ Gaelic, $\mathrm{PDI}=$ Present-Day Irish, EMI = Early Modern Irish.

\begin{tabular}{|l|l|l|l|}
\hline Comparison & Difference in means & $\begin{array}{l}99.7619 \% \text { Lower } \\
\text { CI }\end{array}$ & $\begin{array}{l}99.7619 \% \text { Upper } \\
\text { CI }\end{array}$ \\
\hline EMI-Breton & 0.0879 & 0.039 & 0.1369 \\
\hline PDI-Manx & 0.0552 & 0.012 & 0.0983 \\
\hline Welsh-Manx & 0.0548 & 0.014 & 0.0957 \\
\hline EMI-Cornish & 0.0537 & 0.0074 & 0.1001 \\
\hline Welsh-ScotG & 0.0416 & 0.0021 & 0.0811 \\
\hline PDI-Breton & 0.0389 & -0.0112 & 0.0889 \\
\hline Welsh-Breton & 0.0385 & -0.0096 & 0.0867 \\
\hline Cornish-Breton & 0.0342 & -0.0136 & 0.082 \\
\hline ScotG-Manx & 0.0133 & -0.0198 & 0.0464 \\
\hline PDI-Cornish & 0.0046 & -0.0429 & 0.0522 \\
\hline Welsh-Cornish & 0.0043 & -0.0412 & 0.0498 \\
\hline Welsh-PDI & -0.0003 & -0.0482 & 0.0476 \\
\hline ScotG-Breton & -0.003 & -0.0453 & 0.0392 \\
\hline Manx-Breton & -0.0163 & -0.0598 & 0.0272 \\
\hline ScotG-Cornish & -0.0372 & -0.0763 & 0.0018 \\
\hline ScotG-PDI & -0.0419 & -0.0838 & 0 \\
\hline PDI-EMI & -0.0491 & -0.0978 & -0.0004 \\
\hline Welsh-EMI & -0.0494 & -0.0962 & -0.0026 \\
\hline Manx-Cornish & -0.0505 & -0.0909 & -0.0101 \\
\hline ScotG-EMI & -0.091 & -0.1316 & -0.0504 \\
\hline Manx-EMI & -0.1042 & -0.1461 & -0.0624 \\
\hline & & & \\
\hline
\end{tabular}


Table 3. Token-type ratios ranked for each psalm: numbers of psalms for which each language occupies each rank position. (Rank $1=$ highest TTR, Rank $7=$ lowest TTR.) Abbreviated labels: ScotG $=$ Scottish Gaelic, PDI $=$ Present-Day Irish, EMI $=$ Early Modern Irish.

\begin{tabular}{|l|l|l|l|l|l|l|l|}
\hline Rank & Breton & Cornish & EMI & Manx & PDI & ScotG & Welsh \\
\hline 1 & 1 & 1 & 0 & 0 & 0 & 0 & 28 \\
\hline 2 & 15 & 5 & 5 & 0 & 0 & 4 & 1 \\
\hline 3 & 7 & 9 & 5 & 0 & 0 & 9 & 0 \\
\hline 4 & 5 & 8 & 5 & 3 & 1 & 7 & 1 \\
\hline 5 & 2 & 5 & 6 & 7 & 3 & 7 & 0 \\
\hline 6 & 0 & 1 & 5 & 12 & 10 & 2 & 0 \\
\hline 7 & 0 & 1 & 4 & 8 & 16 & 1 & 0 \\
\hline
\end{tabular}


Table 4. Token counts ranked for each psalm: numbers of psalms for which each language occupies each rank position. (Rank $1=$ highest token count, Rank $7=$ lowest token count.) Abbreviated labels: $\mathrm{ScotG}=$ Scottish Gaelic, PDI = Present-Day Irish, EMI = Early Modern Irish.

\begin{tabular}{|l|l|l|l|l|l|l|l|}
\hline Rank & Breton & Cornish & EMI & Manx & PDI & ScotG & Welsh \\
\hline 1 & 2 & 0 & 1 & 0 & 1 & 14 & 12 \\
\hline 2 & 3 & 0 & 1 & 1 & 0 & 11 & 14 \\
\hline 3 & 14 & 1 & 8 & 2 & 0 & 3 & 2 \\
\hline 4 & 8 & 1 & 8 & 10 & 1 & 1 & 1 \\
\hline 5 & 3 & 4 & 8 & 13 & 0 & 1 & 1 \\
\hline 6 & 0 & 15 & 4 & 4 & 7 & 0 & 0 \\
\hline 7 & 0 & 9 & 0 & 0 & 21 & 0 & 0 \\
\hline
\end{tabular}


Figure 1. Boxplot of B7 values. Means are shown by the "+" symbol. Abbreviated labels: ScotG $=$ Scottish Gaelic, PDI = Present-Day Irish, EMI = Early Modern Irish .

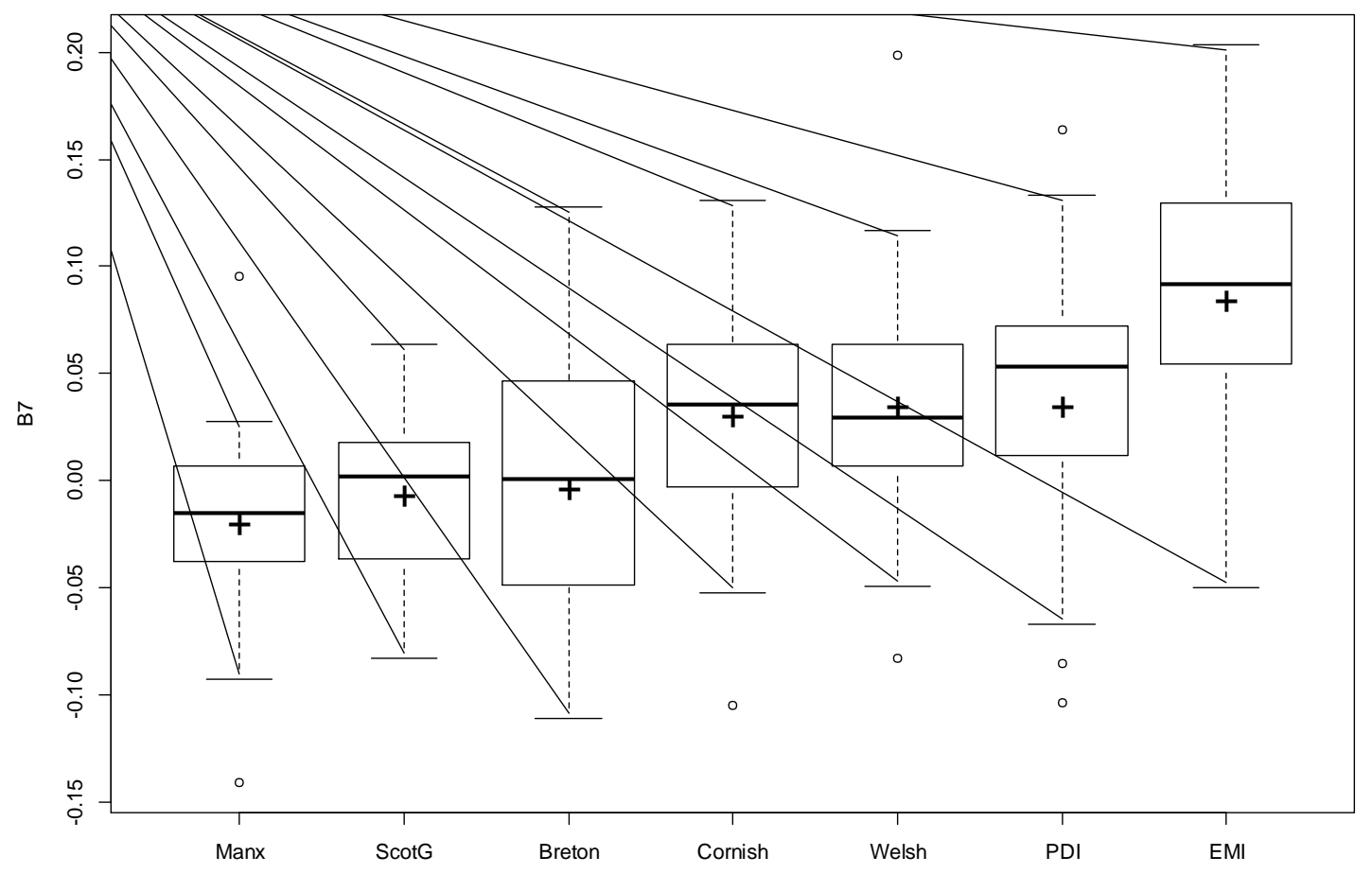


Figure 2. 95\% t-confidence intervals for B7. Abbreviated labels: $\mathrm{ScotG}=\mathrm{Scottish}$ Gaelic, PDI = Present-Day Irish, EMI = Early Modern Irish.

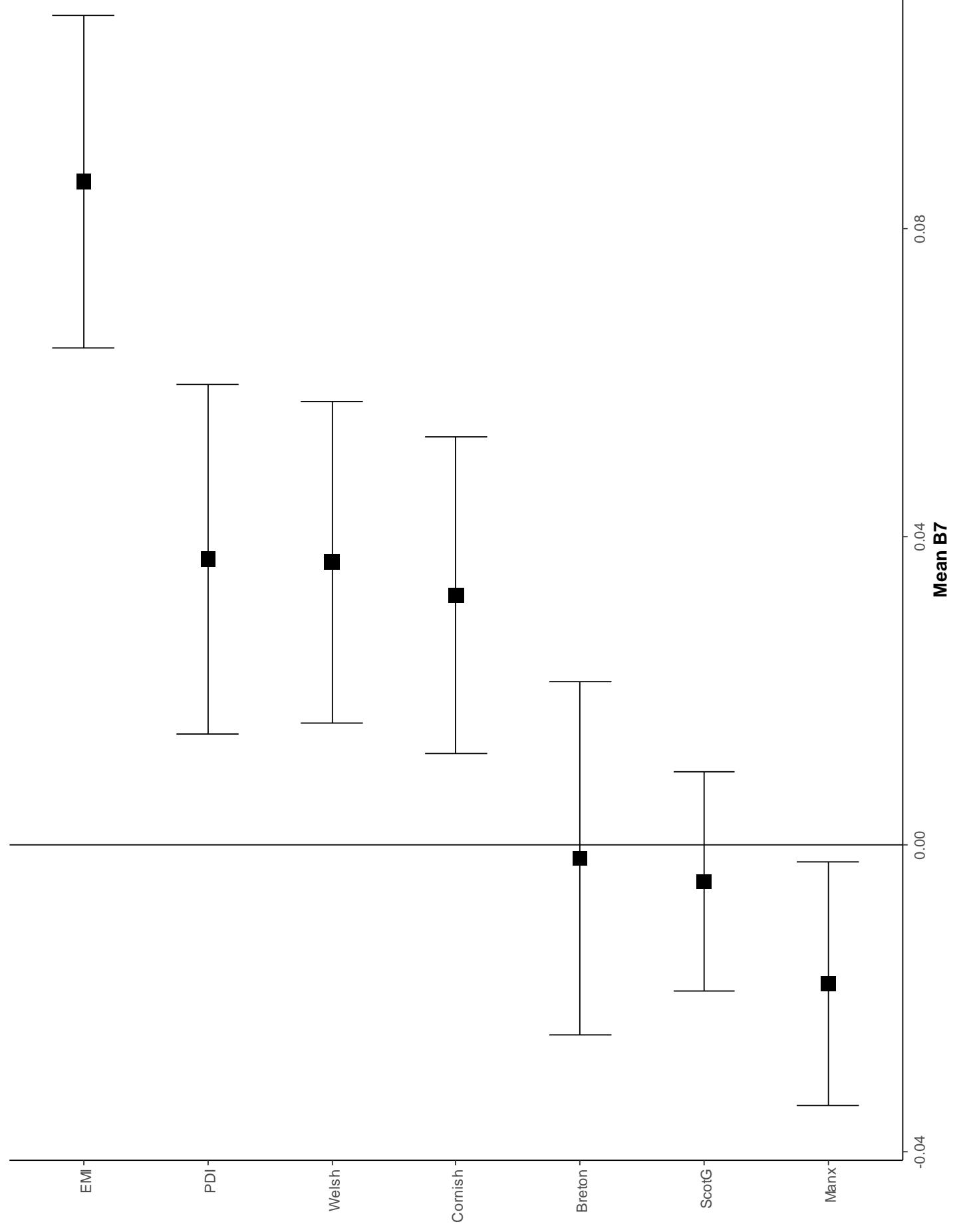


Figure 3. 99.7619\% Welch-Satterthwaite confidence intervals for differences in mean B7 between pairs of languages. Abbreviated labels: $\mathrm{ScotG}=$ Scottish Gaelic, $\mathrm{PDI}=$ Present-Day Irish, EMI = Early Modern Irish.

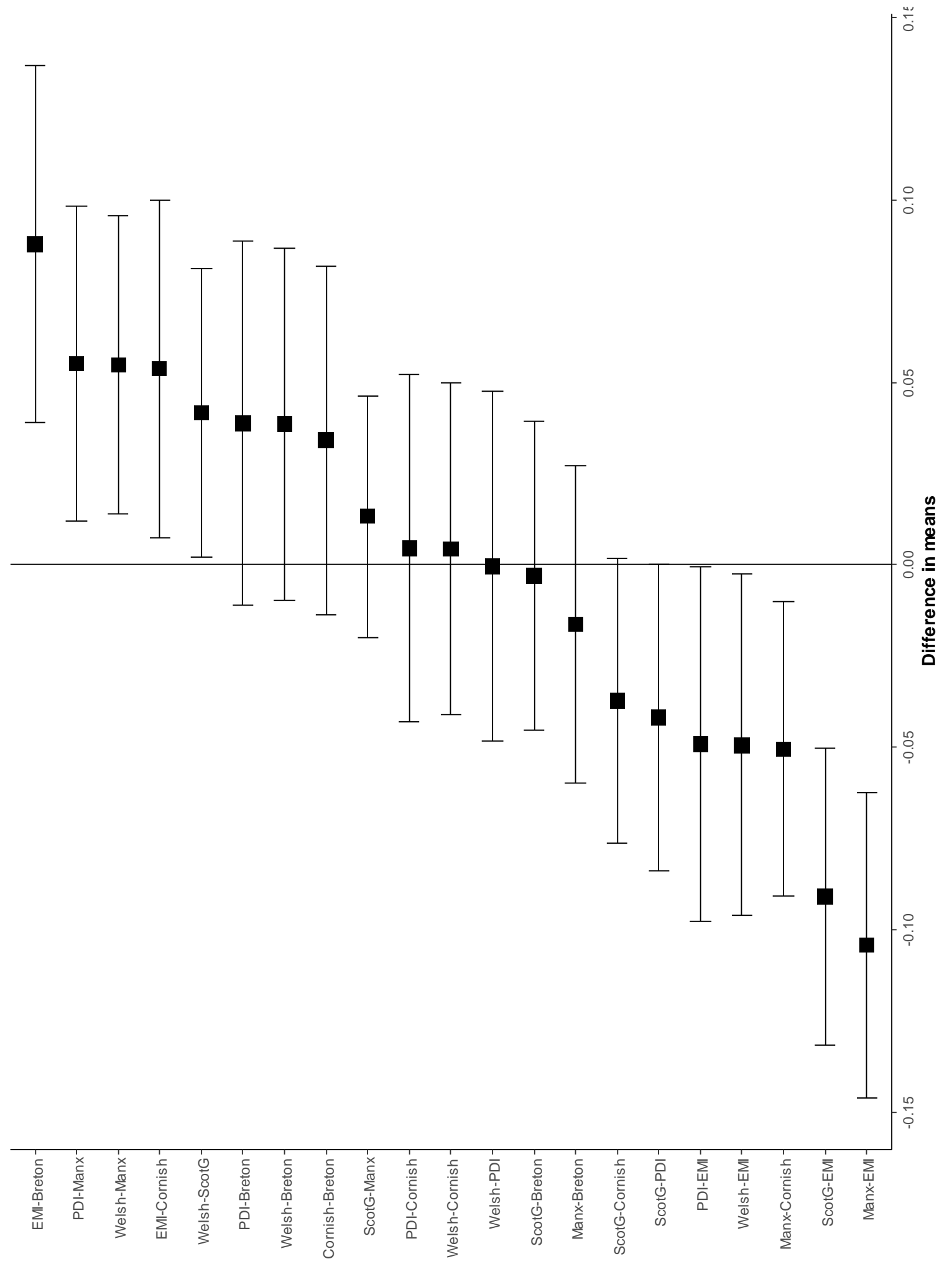


Figure 4. Plot of $\mathrm{N}$ (number of tokens) against $\mathrm{V}$ (number of types) for all 210 texts. (Labels: 1 = Breton, 2 = Cornish, $3=$ Early Modern Irish, $4=$ Manx, $5=$ Present-Day Irish, 6 = Scottish Gaelic, 7 = Welsh.)

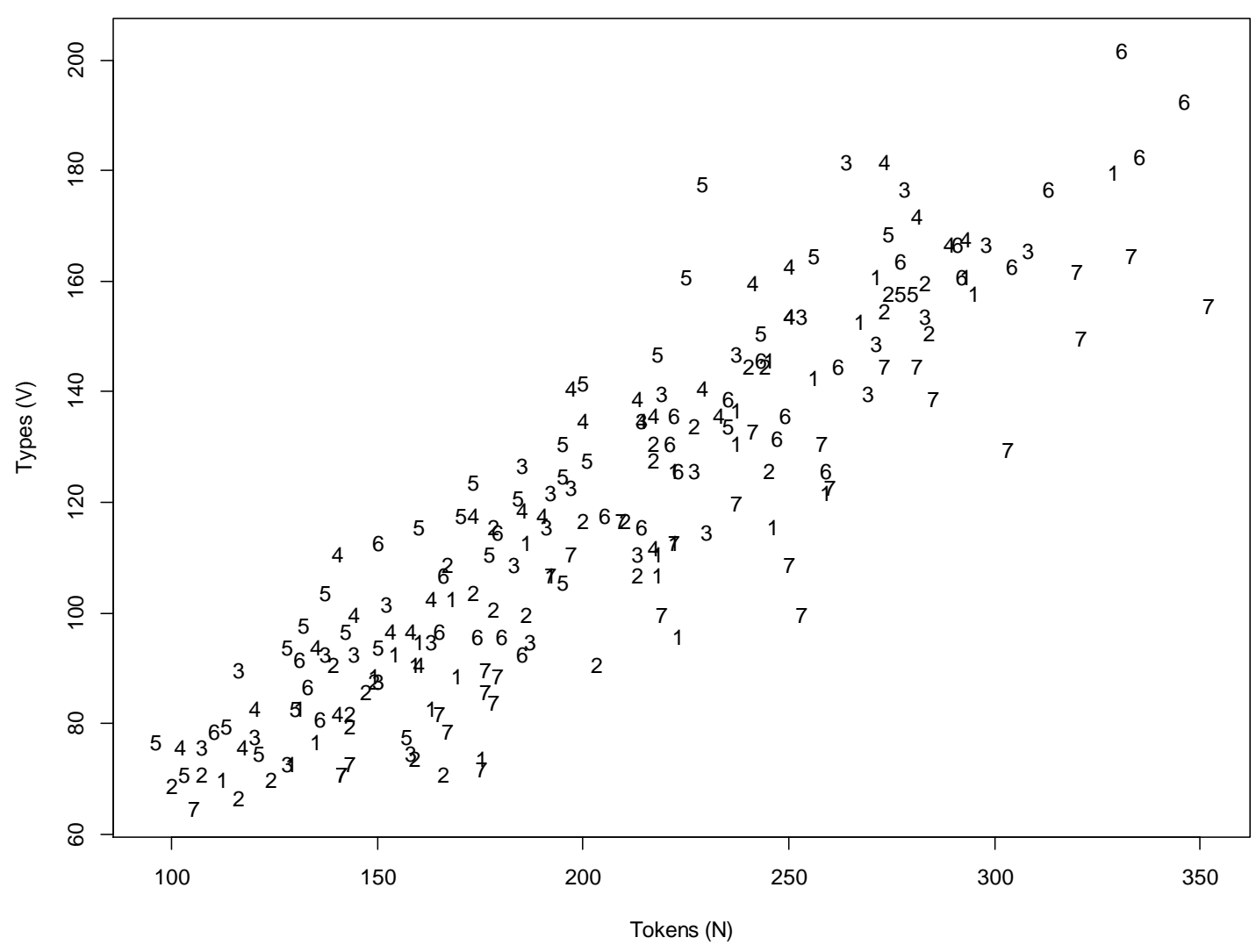

